\title{
Effects of outdoor seating spaces on sociability in public retail environments
}

\author{
Thomas Oram, Ahmad Jehan Baguley, Jack Swain \\ Queensland University of Technology, Australia \\ School of Design Honours Students - Architectural Studies \\ \{thomas.oram; ahmad.baguley; jack.swain\}@connect.qut.edu.au
}

\begin{abstract}
Seating is an important contributor to the social effectiveness of public spaces, due to its ability to support stay activities. This paper focuses on the contributions seating makes to sociability in Queen Street Mall in Brisbane, a public space where limited qualitative assessment has been conducted on seating use and social behaviour. Assessments were made on the sociability of Queen Street Mall through initial observations, online surveys and secondary observations. Common findings across all research methods suggest that the design of Queen Street Mall prioritises pedestrian movement pathways in the interest of adjacent retail centres, creating an environment that struggles to encourage social behaviour. To improve the social use of this space, seating environments should be redesigned to prioritise prolonged outdoor stay activity and increased provisions for shading and sheltering should be provided. Given the impending growth of the Brisbane population, it is important that public spaces in Queen Street Mall are designed to best serve an increasing number of local visitors.
\end{abstract}

Keywords: public seating, social engagement, urban planning, public open space, retail environments

To cite this article:

Oram, T., Baguley, A. J., Swain, J. (2018). Effects of outdoor seating spaces on sociability in public retail environments. The Journal of Public Space, 3(3), 75-I02, DOI I0.3289I/jps.v3i3.668

This article has been double blind peer reviewed and accepted for publication in The Journal of Public Space. 


\section{Introduction}

I.I. Aim

This study aims to identify how seating can affect the social-effectiveness of public spaces. Seating elements in public spaces are invaluable place-making tools for cities, given the opportunities for socialising they provide. In terms of social-effectiveness, seating within public spaces has the potential to benefit community health and wellness by creating safe spaces where people can de-stress through relaxation and physical activity (Chen, Liu and Liu 2016).

\section{I.2. Critique of the Different Theories of Research}

Quality, thermal comfort and management factors are valuable tools for analysing public spaces, due to their wide-reaching influence on behaviour and social interaction in public space. Studies have shown that the quality of public spaces has a strong association with a sense of community, enhancing its social-effectiveness (Friesen 2017). The management of public spaces is a key factor in creating a social gathering place (Zhang and Lawson 2009), and thermal comfort strongly influences the effect of social interactions within these spaces (Rasidi, lamirsah and Said 20I2).

Some studies have established how 'high-quality' public spaces can promote greater associations through providing a sense of community, thus enhancing its socialeffectiveness (Chen, Liu and Liu 2016). Prior research has stated that 'high-quality' public open spaces can create a stronger sense of community by increasing community participation and promoting physical and mental wellness (Francis et al. 20I2). This suggests that attributes of public open spaces can influence the spatial use and behaviour of public space users.

Research into the occurrence of social activities in public spaces suggests that such activities are intrinsically linked to the presence of other people. Public spaces designed to encourage long stays outdoors are shown to be livelier and more sociable spaces than those that don't encourage prolonged outdoor use. By improving the conditions of public space environments to facilitate necessary and optional activities, social activities can be indirectly supported (Gehl 20I I). Studies into the use of public spaces show that seating can support more than fifty percent $(50 \%)$ of total stay activities, increasing the likelihood of passive contact and social activity (Chen, Liu and Liu 2016). There are several influential factors that can affect whether seating is adequately designed, including the quantity, placement, outlook and spacing (Chen, Liu and Liu 2016; Gehl 20I I). By ensuring that seating environments are designed to best serve their users within their context, stay activities can be encouraged and public spaces can become more sociable. Further research has demonstrated that the management of public spaces is also a key factor in creating successful social spaces. (Chitrakar, Baker and Guaralda 2017). Examining the social activities in public outdoor spaces, defining the characteristics of seating spaces, and assessing how these spaces are managed in conjunction with other areas has suggested that a comprehensive management plan is essential for the rejuvenation of deteriorating communal spaces (Lee, Byun and Lee 20I4). Maintaining a balance between the social, civic and economic functions of public space is also an important aspect of good public space management. This is especially true for economically-driven and privatised environments, where commercial interests often dominate the decision making of the public realm (Friesen 2017). As such, public spaces 
require effective management in order to maintain the social and civic responsibilities of public space and prevent corporate and private powers from imposing themselves too heavily.

The role of thermal comfort as an influential factor on social interactions has also been examined. Research investigating how typical humid-sun spaces can show demotion of social interaction suggested that diversity of open spaces allows for better social interaction (Huang et al. 2016). These studies have demonstrated that outdoor thermal comfort and public space utilisation can be improved in hot and humid regions through the use of varying levels of shade. (Lin 2009).

As previously discussed, quality, thermal comfort and management factors are major catalysts for social interaction in public spaces. However, limited research has been conducted on how the perceptions and use of seating in public retail spaces influences social interaction. Therefore, the purpose of this current research is to better understand the social influence of public retail space seating environments, focusing on quality, thermal comfort and management factors.

\section{I.3. Research Question}

The aims of this research are (i) to explore the perceptions of public seating in Queen Street Mall (henceforth QSM), Brisbane by assessing individual preferences, experiences and relationships with this seating; and (ii) to explore whether the public seating elements in QSM can effectively serve both functional and social purposes, now and into the future. These aims are addressed through the following research questions:

I. Does the seating design in QSM contribute to socially-effective public space?'

2. Do the design characteristics of seating design in QSM encourage social behaviours based on current theories (as outlined in section I.2)?

3. What stay activities are there in QSM that could improve the social interaction of visitors?

In attempting to answer research question 3, the following sub-questions are asked:

I. When and where do users choose to sit in QSM?

2. Who is using the seating and for what activities?

3. What are the user perceptions of seating design in QSM?

\section{I.4. Setting}

QSM provides an appropriate setting to explore quality, thermal comfort and management factors and to investigate how the design of public shopping malls influences the way people socially engage with one another. According to the Queen Street Mall Visioning Plan from 20I5, 7,500 day-trippers, 8,900 residents, 9,000 tourists, I5,000 students, 40,000 shoppers, 20,000 night-time visitors/workers, and I50,000 employees visit QSM on a daily basis (Brisbane Marketing 20I5). These statistics led the Lord Mayor of Brisbane to proffer QSM as "the most successful mall in Australia". However, there is no information regarding any specific usage and activities. The lack of qualitative data regarding the use patterns of QSM public spaces and the typical behaviour of its users poses a knowledge gap that must be addressed in order to substantiate claims for the success of QSM. 


\section{Methodology \\ 2.I. Study Area}

The study will specifically focus on the public spaces of QSM, situated in the central business district of Brisbane, a major city in South-East Queensland. This subtropical retail precinct extends roughly 450 metres by 210 metres with pedestrian zones roughly 25 metres wide.

A case study approach using mixed methods was selected as the most suitable approach for this project. The case study will explore the design of public seating spaces in QSM, the characteristics of the seating design that encourage social behaviour, and the usage activities which promote social interaction.

\subsection{Study Design}

This study followed a mix-method design involving the collection of qualitative and quantitative data. All data collection processes were compliant with QUT Research Ethics guidelines. The study is in two parts:

Part A involved a site observation and an online survey. The initial observations occurred impromptu, irrespective of time and day, allowing for mapping of the public seating environments and the forming of a base understanding of the setting, users and activities of public space in QSM. Early analysis of site observations assisted the design of the online survey, which focused on the individual perceptions and behaviours of QSM users. These methods collectively informed the appropriate times and locations for Part B of the study. Part B included observations of daily usage patterns. This method took place at QSM over 4 periods throughout a day. Testing was conducted on a Friday with a managementplanned daytime public event in order to test during a best-case scenario for pedestrian traffic.

The collective findings of Part A and Part B informed understandings of how the seating environments in QSM do and do not positively contribute to social engagement. These findings also outlined the design characteristics and the usage activities that encourage social interactions within the public space of QSM.

\subsection{Site Observation}

The initial site observation, conducted in mid-April 2018, developed our understanding of the site and the public seating locations within QSM. This helped to locate and determine which parts of the Mall contained the seating and place-making elements needed for conducting subsequent research. The field studies consisted of three open spaces with three researchers taking photographs and hand-written notes on the use of primary and secondary seating in the mall. Site mapping and photographic records provided context and generated a physical understanding of the research site. The focus areas for these observations included the uses and placement of seating areas within and around QSM, opportunities for visiting the mall, the design of the spaces in which people interact, and any recurring patterns that could be used to understand the typical use of seating areas.

\subsection{Online Survey}

The online survey was created in Google Forms and distributed after the analysis of initial observation data. The survey was shared via Facebook as an open invitation by uploading a link and an explanation of the study purpose to the researchers' personal profiles. The 
researchers also asked personal contacts from an older age demographic ( $>50$ years old) to distribute the link and research purpose in order to receive a more even age spread among survey respondents. The online survey had an attached consent form and participant information sheet that provided additional details about the research project. The survey was conducted at the end of April until mid-May 20I8 and disseminated to over 100 persons of varying age, gender and ethnicity, included both frequent and infrequent users of QSM.

Survey questions were developed and refined following initial site observations. These closed and open-ended questions included topics on demographics, use of QSM, use of seating, and perceptions of QSM. The questions assessed were:

(i) The type of users of seating spaces in the QSM

(ii) The use of seating spaces in QSM

(iii) Perceptions of seating environments in QSM

(iv) Additional comments (open-ended responses)

(For full question list, refer to Table 2 in Appendix)

\subsection{Secondary Observations}

The secondary site observation explored the typical behaviour of QSM users, focusing on the type of activities performed and the uses of public seating spaces. This method was based upon the methods employed by Chen, Liu and Liu (2016) in their observational analysis of North Central Axis Square in Shenzhen, China.

Observations were conducted at 8:30 12:30, 15:30, and 17:15 on Friday II May 2018 to provide an overview across the busiest parts of the day. The observations were conducted with three researchers with two of the three physically tallying the data of pedestrian movement with a digital tally counter application and a timer. The third researcher used an observation table to record the instances and type of seating use that took place in three separate observation zones. This helped to understand the general trends and significant activity patterns that were observed during site visits, and to make comparisons with information collected during the online survey.

Instances of different activity types were tallied on a spreadsheet for each of three (3) QSM observation zones (Myer Centre, Albert St. Intersection and Wintergarden). These activity observations included: Sitting (passive observation); Talking; Interacting with phone/device; Observing public performances; Eating; and Other (miscellaneous activities requiring temporary stoppage). The context of observations was to understand: the uses and placement of seating areas within QSM public space; the interactions between people; and the typical use patterns of QSM which could lead to follow-up research.

\section{Results/Analysis}

3.I Site Observation

This section outlines the results and analysis of the initial site observation that involved site mapping and analysis over two separate visits. Both visits took place during the morning on their respective days, between 8:00am and 10:00 am. The data collected included field notes and photographic records of QSM, which helped inform the site map (Figure I). Public seating was found to typically be designed as seating clusters for multiple small groups of people, up to five (5) people per bench seat. These spaces had a high activation potential due to the large amount of pedestrian movement, providing good opportunities for data collection. 


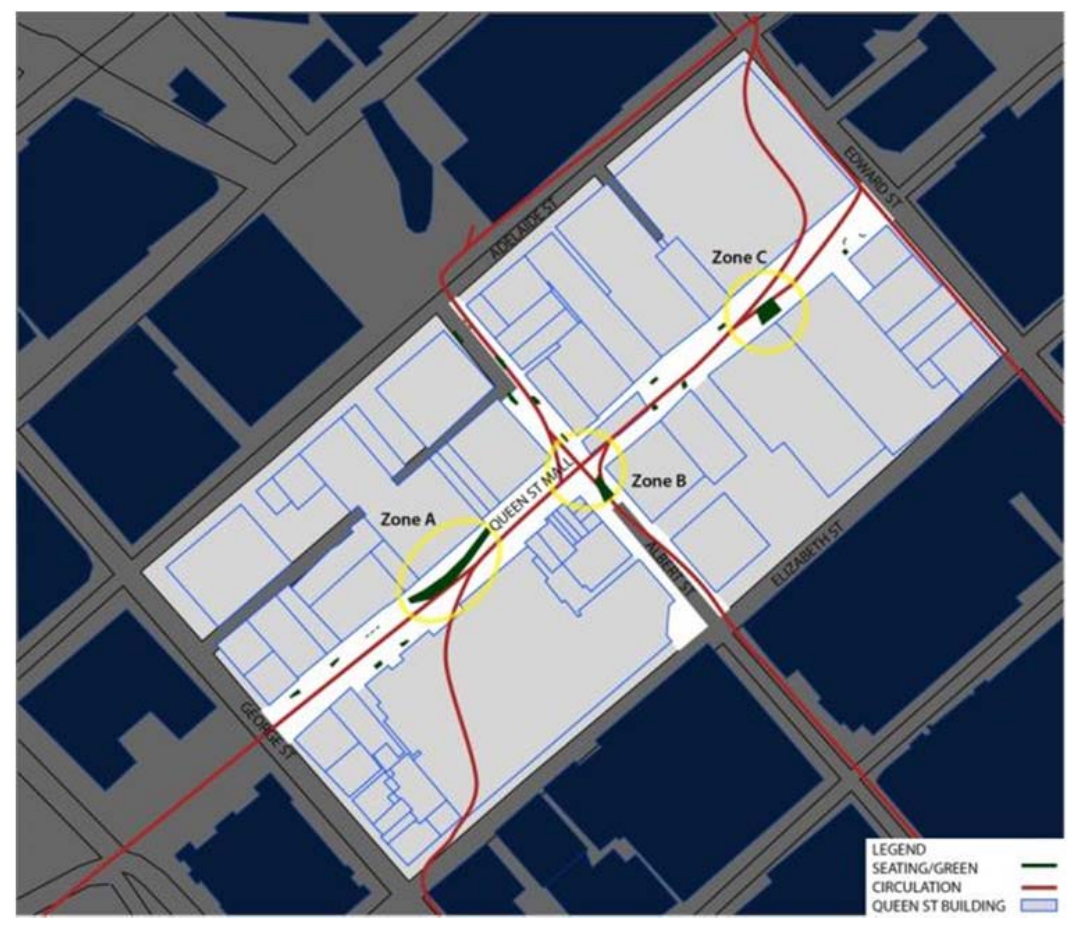

Figure I: Site Observation Map

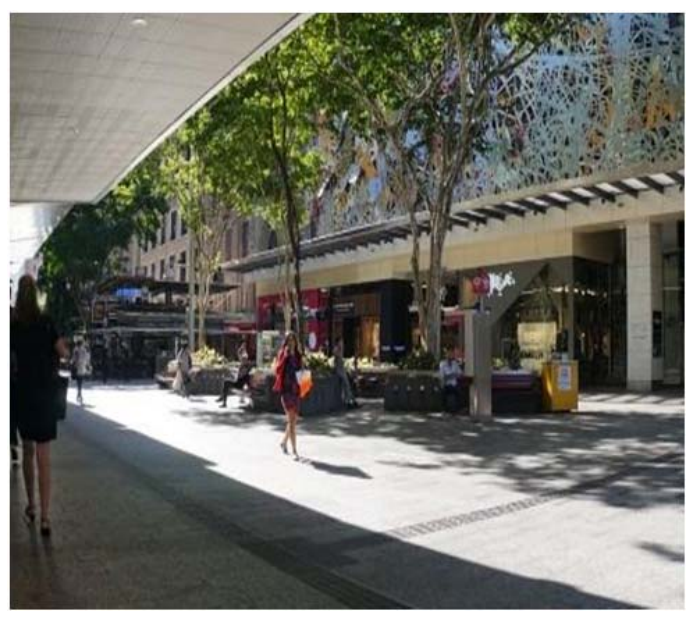

Figure 2: Location A

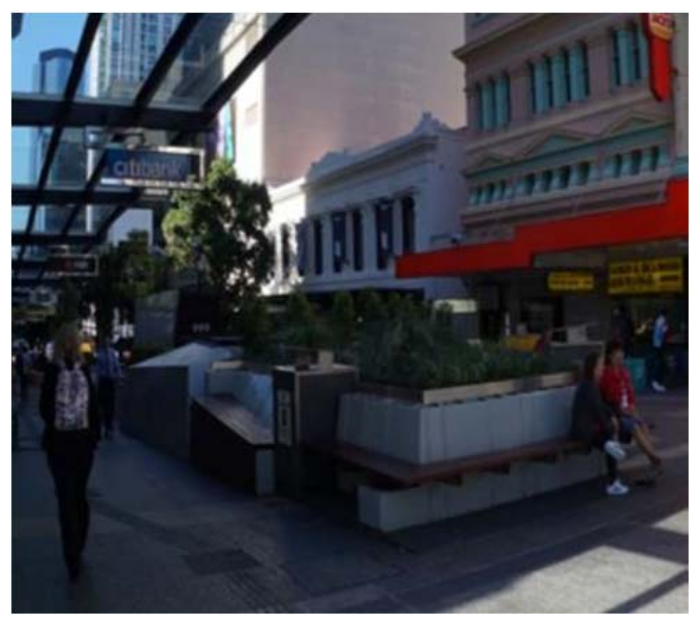

Figure 3: Location B

Field notes and photographic records from site observation prompted the selection of three key locations that showed relevant seating and place-making elements needed to effectively conduct research. These locations were: Location A (outside of Brisbane Myer Centre); Location B (intersection point between Queen St and Albert St); and Location C (between Wintergarden and David Jones) (see Figures 2, 3, 4, 23, 24, 25). 


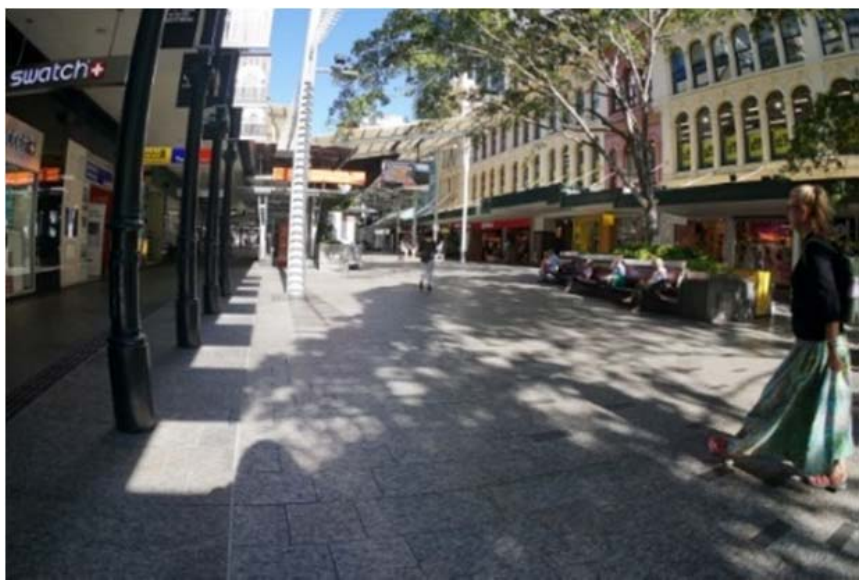

Figure 4: Location C

Initial observations of QSM found very little social activity taking place among users of public seating. The main observed uses of public seating were:

- Watching the large television screen near the Myer Centre entrance

- Reading a newspaper or book

- Using a mobile phone (phone calls and/or screen interaction)

Some conversations between seating users were observed, but most people chose to sit on their own and space themselves from others. There was also intensive use of the privately-operated dining spaces along the Mall, especially during weekend observations. However, the inwards facing seating of these private spaces creates little connection between diners and QSM public spaces (Figure 5).

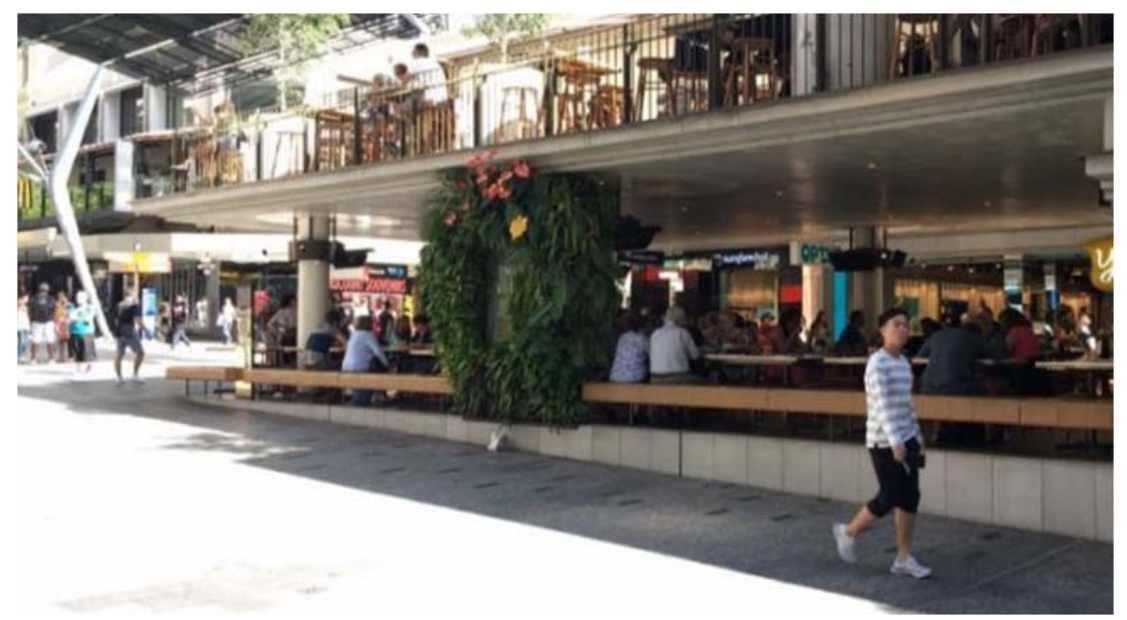

Figure 5: Seat orientation for private dining at "Jimmy's on the Mall" creates disconnection with surrounding public space

Observations into the design of QSM public seating spaces revealed several insights into the typical behaviour of seating use in QSM. Shaded seats were the first to be filled by new users, with sun-exposed seats rarely taken while shaded seats were still available. Secondary seating was favoured over primary seating when the conditions, such as shading, were more favourable. Users not pre-occupied with other activities (e.g. eating, 
phone calls) would choose to sit near performers, even if the seating conditions were unfavourable. Duration of seating use was generally dictated by the reasons for using seating. Seating turnover was typically every 5-10 minutes, unless users were engaged with activities such as eating, taking phone calls or watching public performances. The large television screen near the Myer Centre entrance was seen to prolong seating use but did not result in instances of social interaction.

\subsection{Online Survey}

Online survey data collected both quantitative and qualitative information in three mains areas; demographics, the use of QSM public spaces and perceptions of QSM.

95 people completed the online survey. The survey data was transferred to a spreadsheet based on the survey questions. Once the data was entered for each survey, these were checked by the three research team members to ensure data was correctly entered.

\subsection{Demographics}

Age groups for the online survey were selected so as to group people by their 'stage of life'. These chosen stages were teenagers (I I-19); young adults (20-35); adults/middleaged (36-59); and retiree/elderly $(60<)$. Because of this, the age ranges within these groups is unequal.

- The identified gender of respondents was relatively even, with slightly more (57.9\%) identifying as female.

- Of the four different age groups, the majority (67\%) of respondents fell within the '20-35 years' age group.

- $44.4 \%$ of respondents identified as 'regular users of Brisbane CBD public transport terminals/stations'

- More respondents were casual visitors (27.1\%) and CBD employees (19.4\%) than Brisbane CBD residents (9.0\%) (Figure 6)

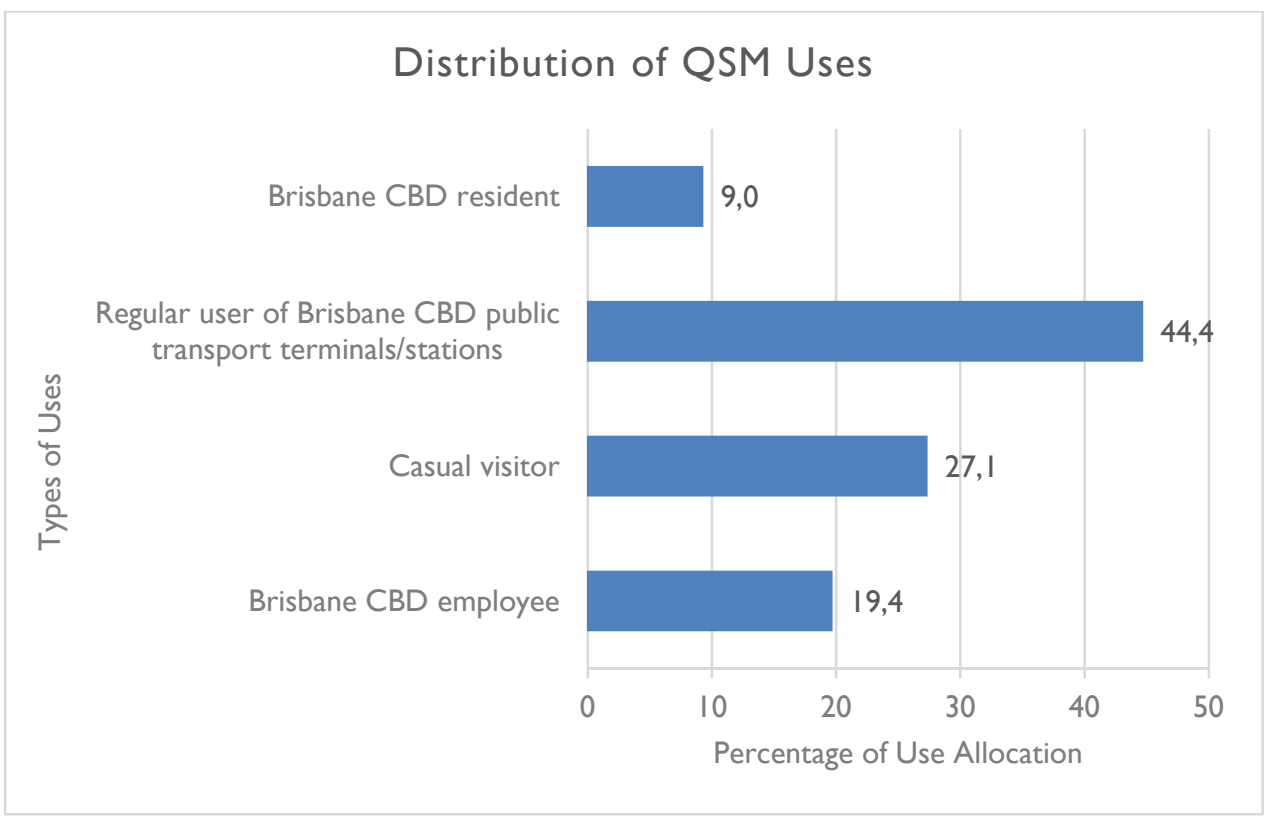

Figure 6: Distribution of Use

82 | The Journal of Public Space, 3(3), 20I8| ISSN 2206-9658

City Space Architecture / UN-Habitat 


\subsubsection{Use of Seating}

In terms of the use of seating spaces in QSM, both quantitative and qualitative data were collected and analysed. Most respondents claimed to visit the mall at least once a week (51.6\%) with few claiming to visit 'almost never' (9.5\%) (Figure 7). The most common visiting time was during the afternoon, and more people visited on weekdays than weekends, as shown in Figure 8.

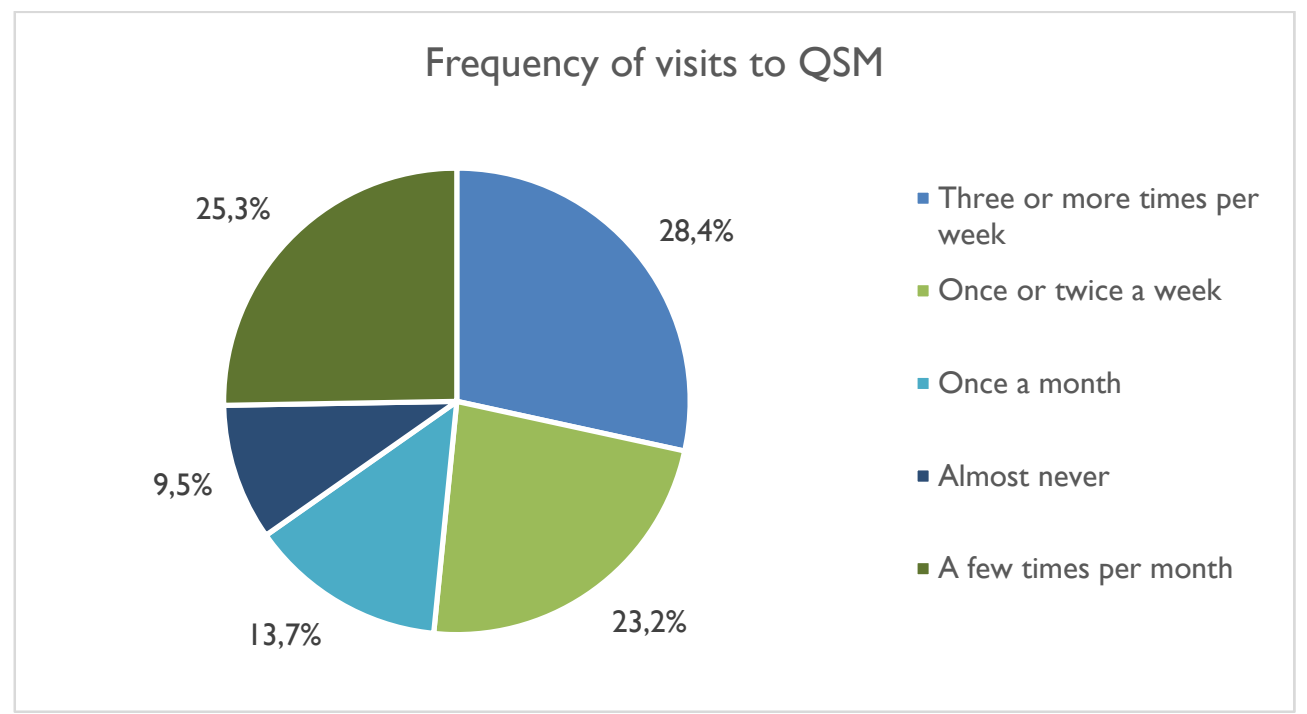

Figure 7: Visiting consistency of survey respondents

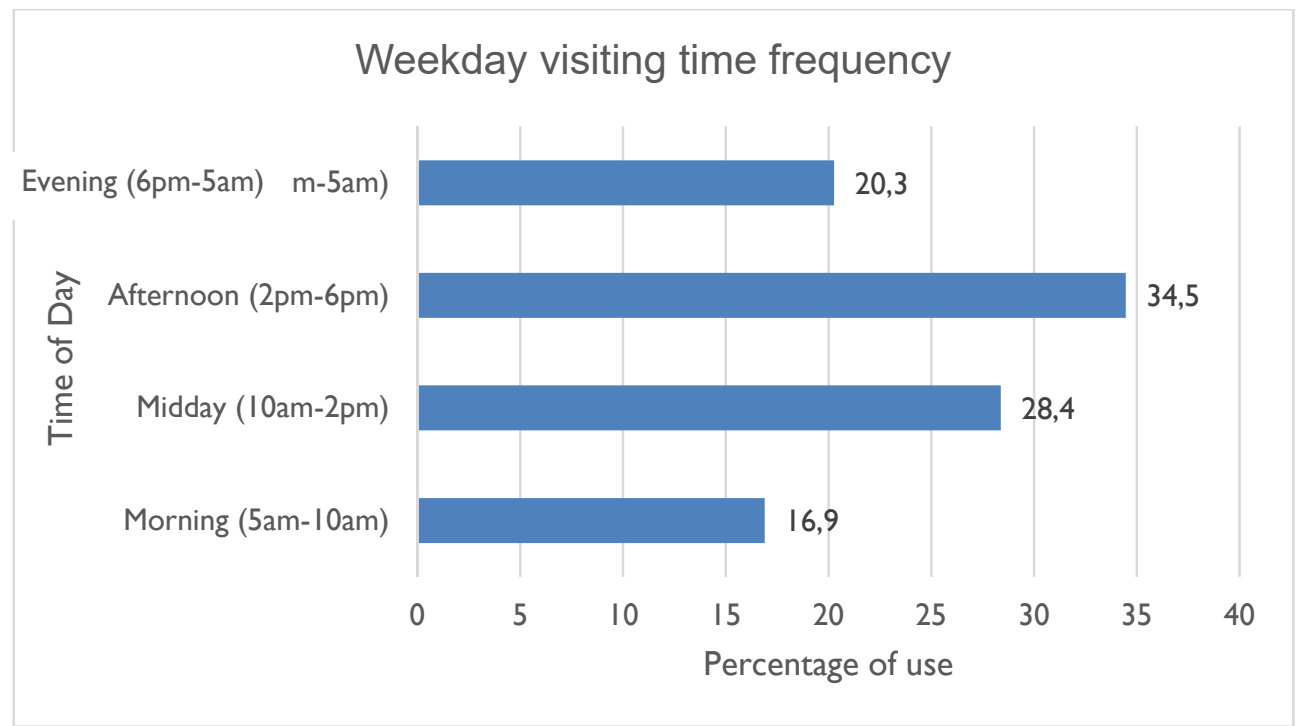

Figure 8: Visiting times of survey respondents

A majority of the respondents $(65.2 \%)$ stated that they rarely used the public seating in QSM. When QSM seating was used, the most common use activities were eating (22.2\%), resting (20.9\%), meeting other people (20.5\%) and using mobile phones (20.1\%) (Figure 9). Responses regarding the use of secondary seating were evenly spread, with $49.4 \%$ stating they have used secondary seating elements in QSM instead of traditional seating (Figure 
Effects of outdoor seating spaces on sociability

10). A majority of respondents $(65.3 \%)$ claimed that public seating was available when they needed to use it.

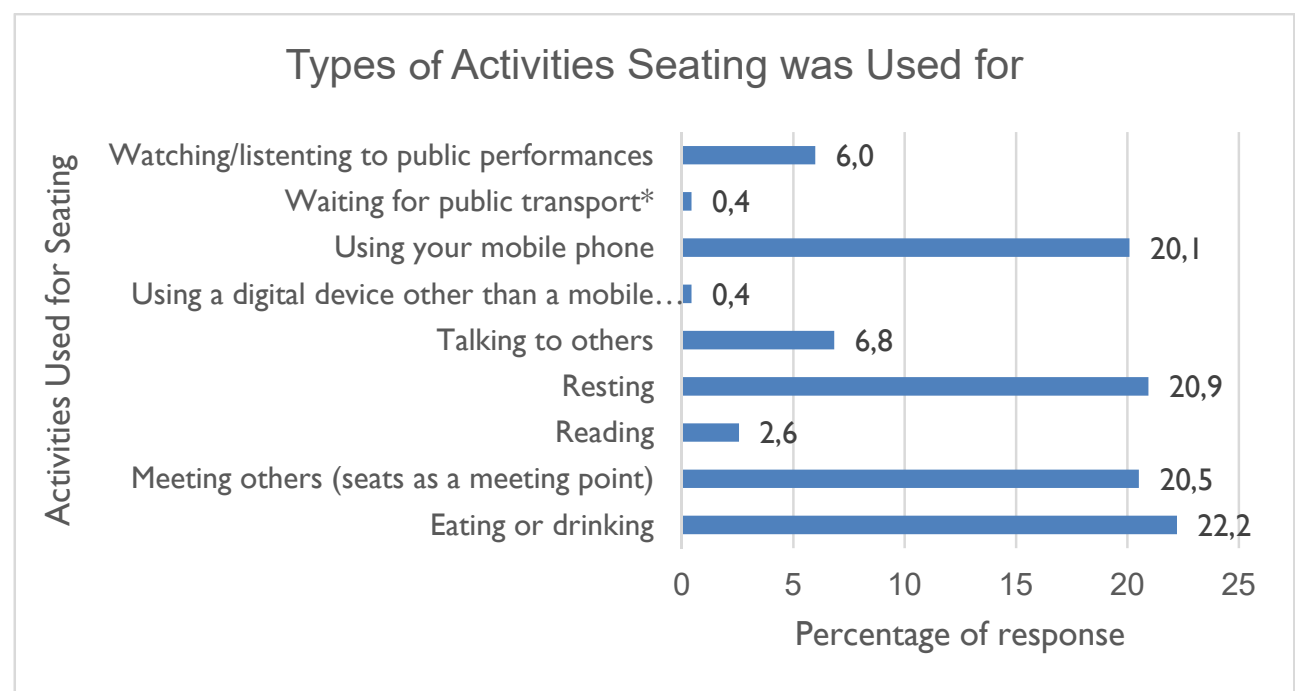

Figure 9: Seating activities of survey respondents

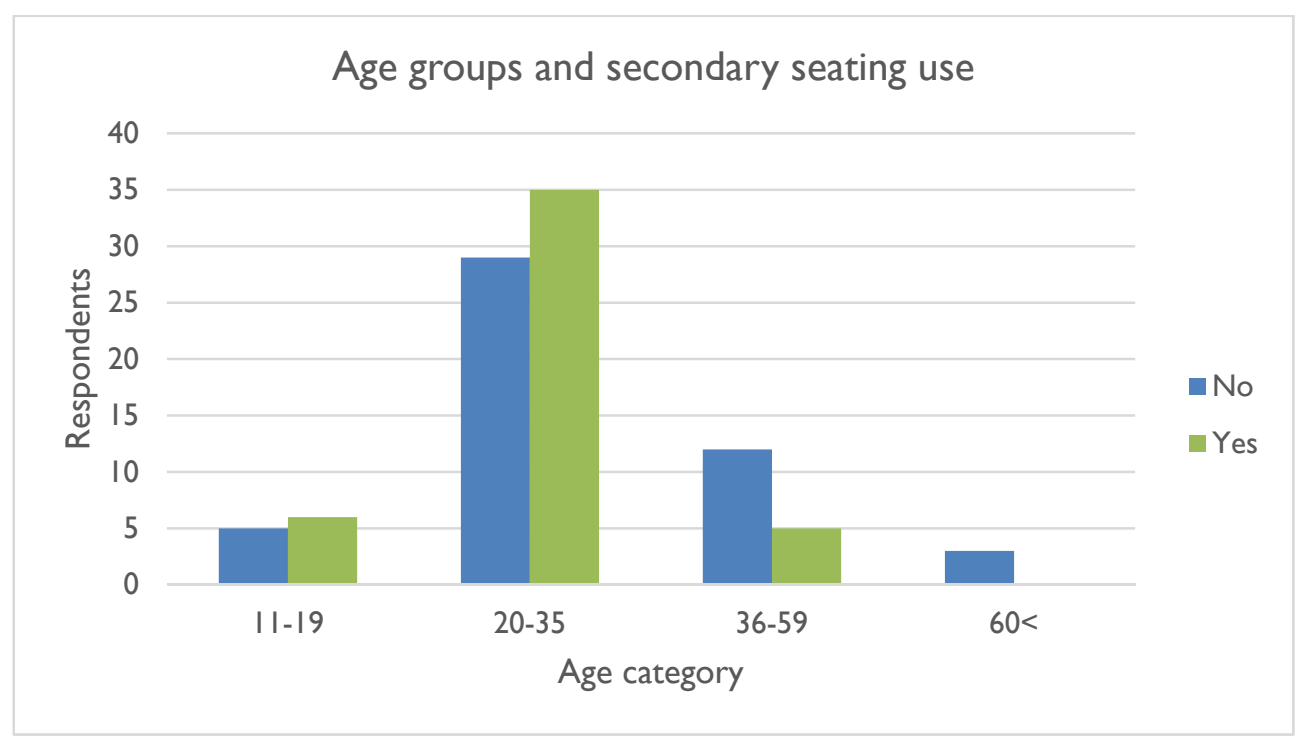

Figure 10: Secondary seating use by age of survey respondents

\subsubsection{Perceptions of QSM and seating environments}

Half (50.5\%) of all respondents felt that QSM was well designed to facilitate stay activities and most (52.6\%) respondents felt QSM was inviting to all users.

The majority of respondents felt that seating in QSM wasn't adequately sheltered, with more than half of respondents $(54.7 \%)$ saying the seating wasn't sufficiently shaded and more than three quarters (78.9\%) believing that seating wasn't sufficiently protected from wind and rain. 


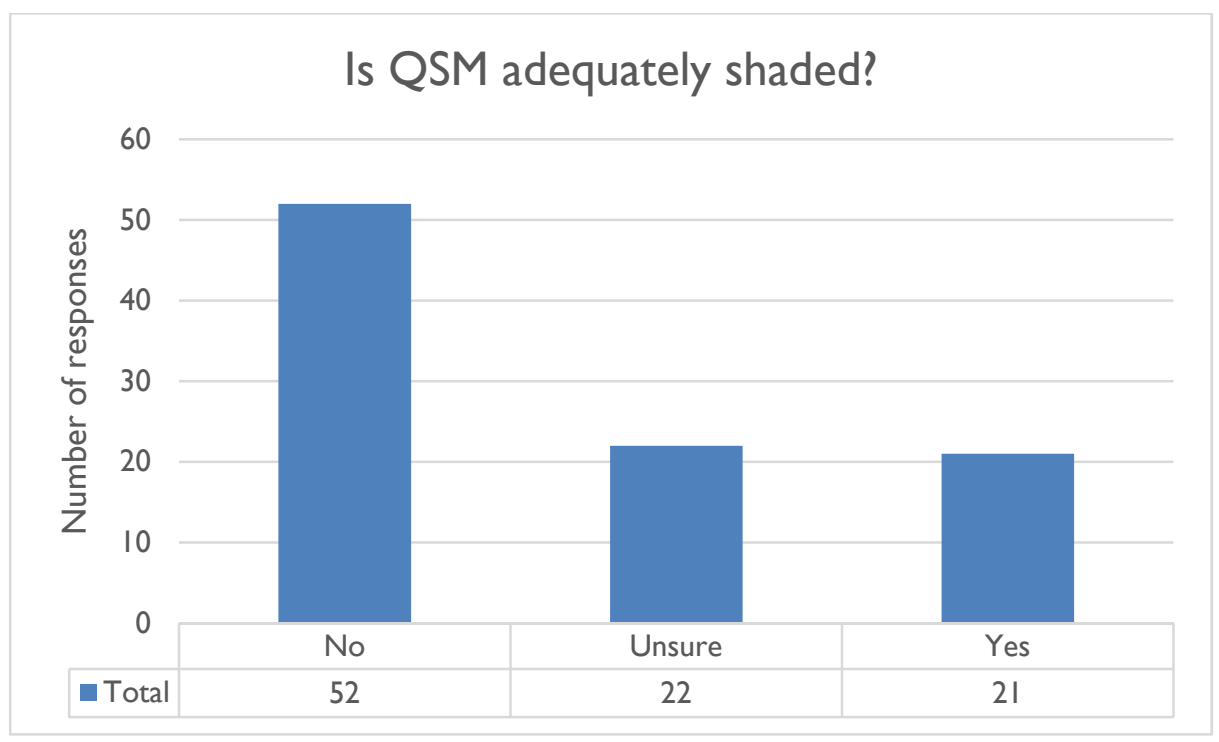

Figure II: Survey responses on adequacy of QSM shading

\subsubsection{Perceptions of branding and advertising in QSM}

Most (60\%) respondents felt the branding and advertising in QSM had no significant impact to user experience. Opinions on whether branding and advertising enhanced or detracted from the user experience in QSM were evenly divided (20\% each) (Figure I2).

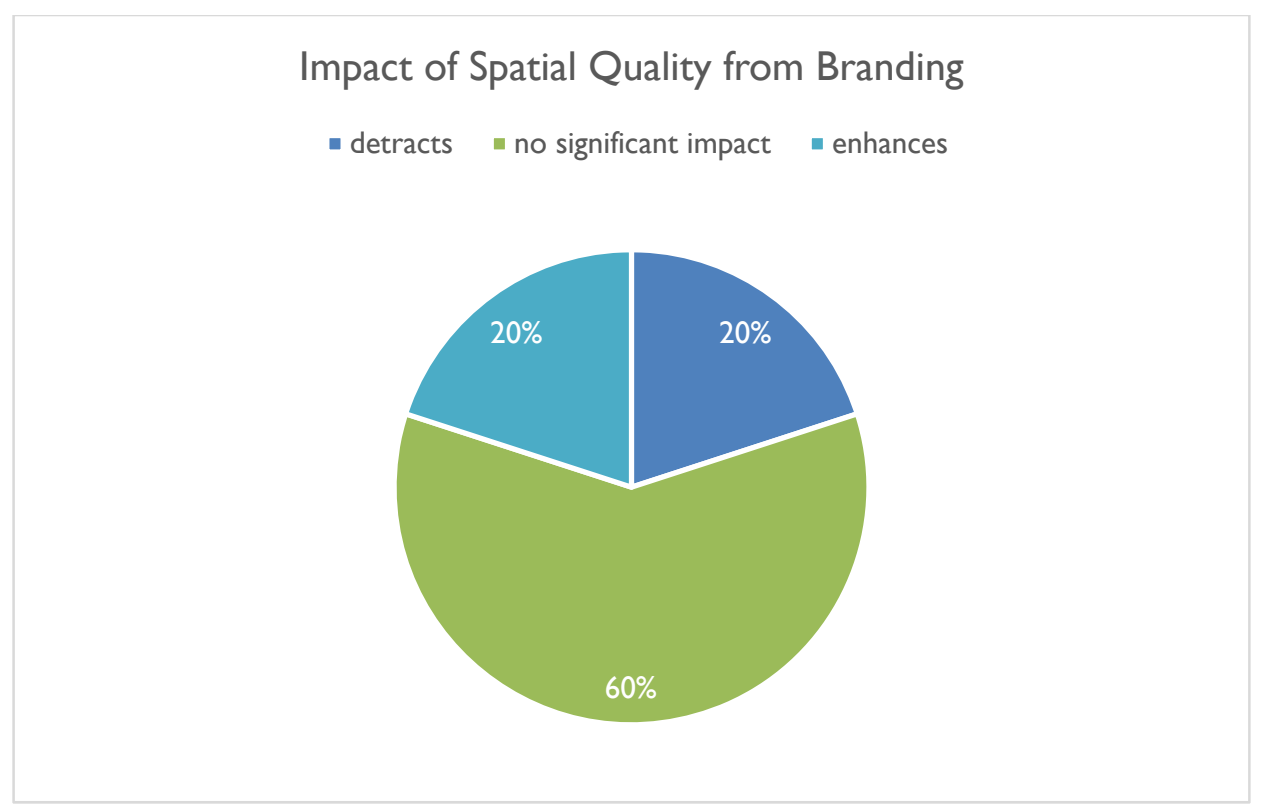

Figure 12: Branding impact on experience

\subsubsection{Additional comments on QSM seating environments}

The additional comments regarding QSM seating environments yielded mixed results. While some people felt the design of QSM public space was well suited to their reasons for use, others felt that the seating spaces were uninviting, insufficient or did little to support stay activities. Some of the participants also felt that the design of public space 
seemed centred around the retail aspects of QSM, with not enough consideration for green space and activities like eating and relaxing.

\subsection{Secondary Observations}

The secondary observations, conducted Friday II May 2018, focused on collecting quantitative data regarding the pedestrian movements and instances of seating use in three zones of QSM. Data was analysed by observing the amount of seating use, the types and amount of different seating activities and the number of pedestrians transitioning through different spaces. Values were compared between different zones and observation times.

\subsection{Activity Count}

Location $A$, the area with the most seating, saw the greatest levels of seating use across the day. The greatest number of seating use recorded in an observation period was 35 instances, during the mid-afternoon in Location B.

The busiest time for seating use in all locations was the mid-afternoon time slot (I 5:3415:52) (Figure 13). Heightened use during this time coincided with the end of the school day and $C B D$ workers leaving their workplaces.

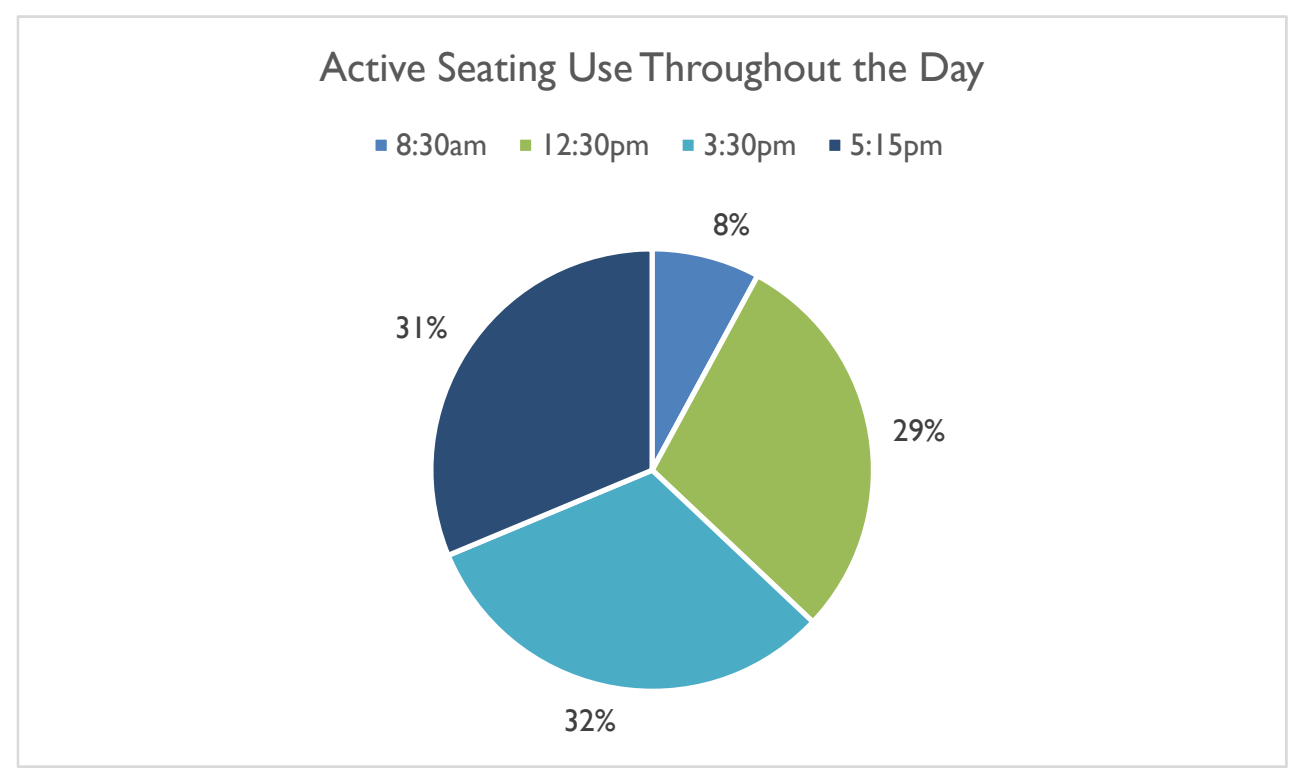

Figure 13: Percentage of active seating use throughout the day

More than a third of users (36\%) were observed interacting with a phone or device whilst seated in QSM. Only one fifth (20\%) of users were sitting down and interacting (talking) with other people talking. Instances of conversation mainly occurred between two (2) individuals, with no groups larger than four (4) people observed having conversations whilst using seating (Figure I4). 
Thomas Oram, Ahmad Jehan Baguley, Jack Swain

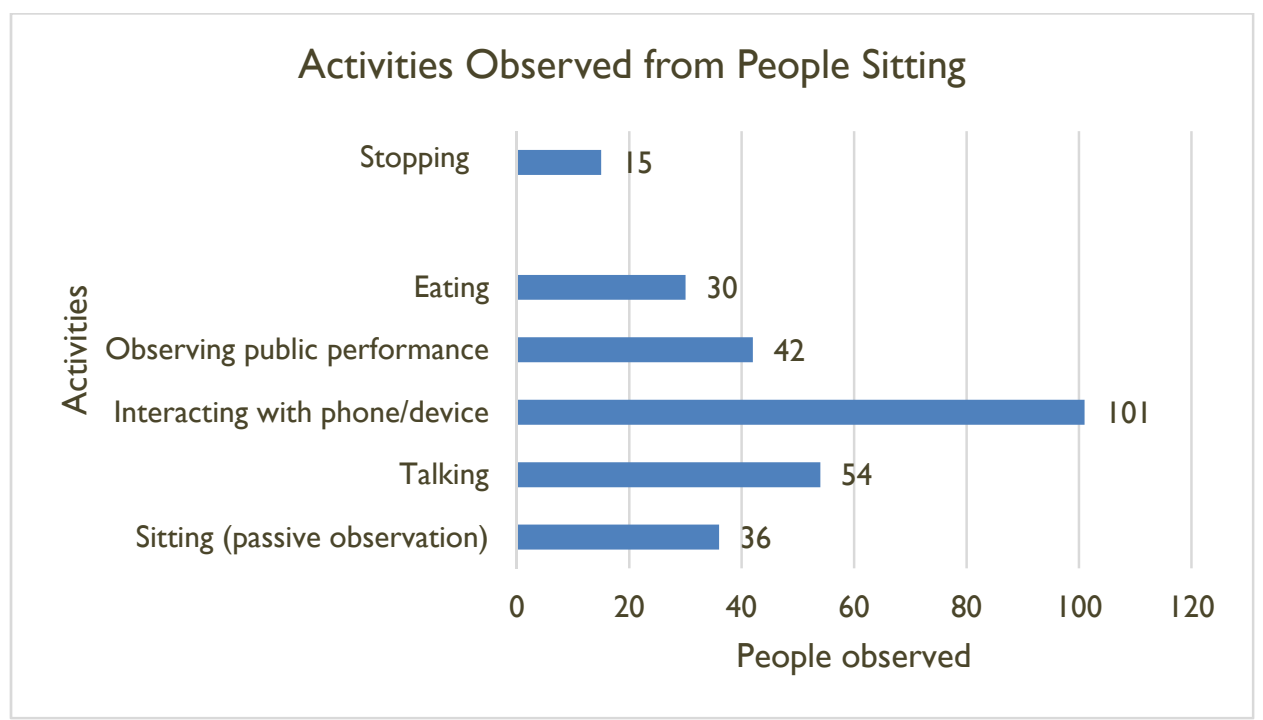

Figure 14: Observed activities counted

\subsubsection{Pedestrian Count}

While the use of seating in QSM was being recorded, the number of people transitioning through both sides of the observation zones was also recorded.

Table I: Pedestrians passing through Zone I, 2 and 3

\begin{tabular}{|c|c|c|}
\hline Time & $\begin{array}{l}\text { Pedestrian } \\
\text { Movements } \\
\text { (both sides) }\end{array}$ & Seating Use \\
\hline \multicolumn{3}{|c|}{ Zone I } \\
\hline $8: 30$ & 194 & 10 \\
\hline $12: 20$ & 678 & 28 \\
\hline 15:34 & 457 & 28 \\
\hline $17: 10$ & 601 & 31 \\
\hline TOTAL & 1930 & 97 \\
\hline \multicolumn{3}{|c|}{ Zone 2} \\
\hline $8: 37$ & 260 & 5 \\
\hline $12: 32$ & 884 & 13 \\
\hline $15: 43$ & 603 & 35 \\
\hline I7:18 & 658 & 20 \\
\hline TOTAL & 2405 & 73 \\
\hline \multicolumn{3}{|c|}{ Zone 3} \\
\hline $8: 47$ & 268 & 7 \\
\hline $12: 40$ & 1016 & 20 \\
\hline $15: 52$ & 564 & 25 \\
\hline I 7:27 & 909 & 16 \\
\hline TOTAL & 2757 & 68 \\
\hline
\end{tabular}

Pedestrian and Seating Use Totals

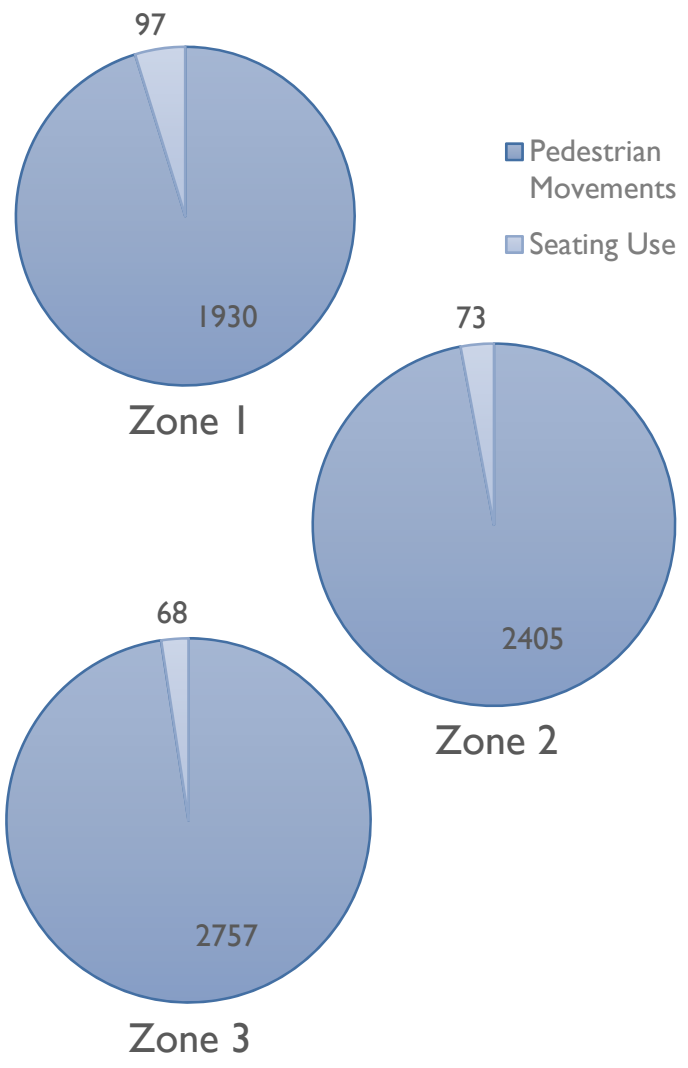

Figure 15: Pedestrian movements and seating use totals 
The busiest times for pedestrian movements were at midday and early evening. As with the activity count, the morning period made up the smallest portion of total pedestrian movements (I0\%) (Table I). As is to be expected, the instances of pedestrian movement in QSM far outnumbered the instances of seating use. The percentage of QSM users observed using the public seating was between 2-5\% per location (Figure I5).

\subsubsection{Further Findings}

$50.5 \%$ of survey respondents stated that the seating in QSM effectively supported stay activities within the public space. $52.6 \%$ of survey respondents found QSM to be uninviting (Figure 16).

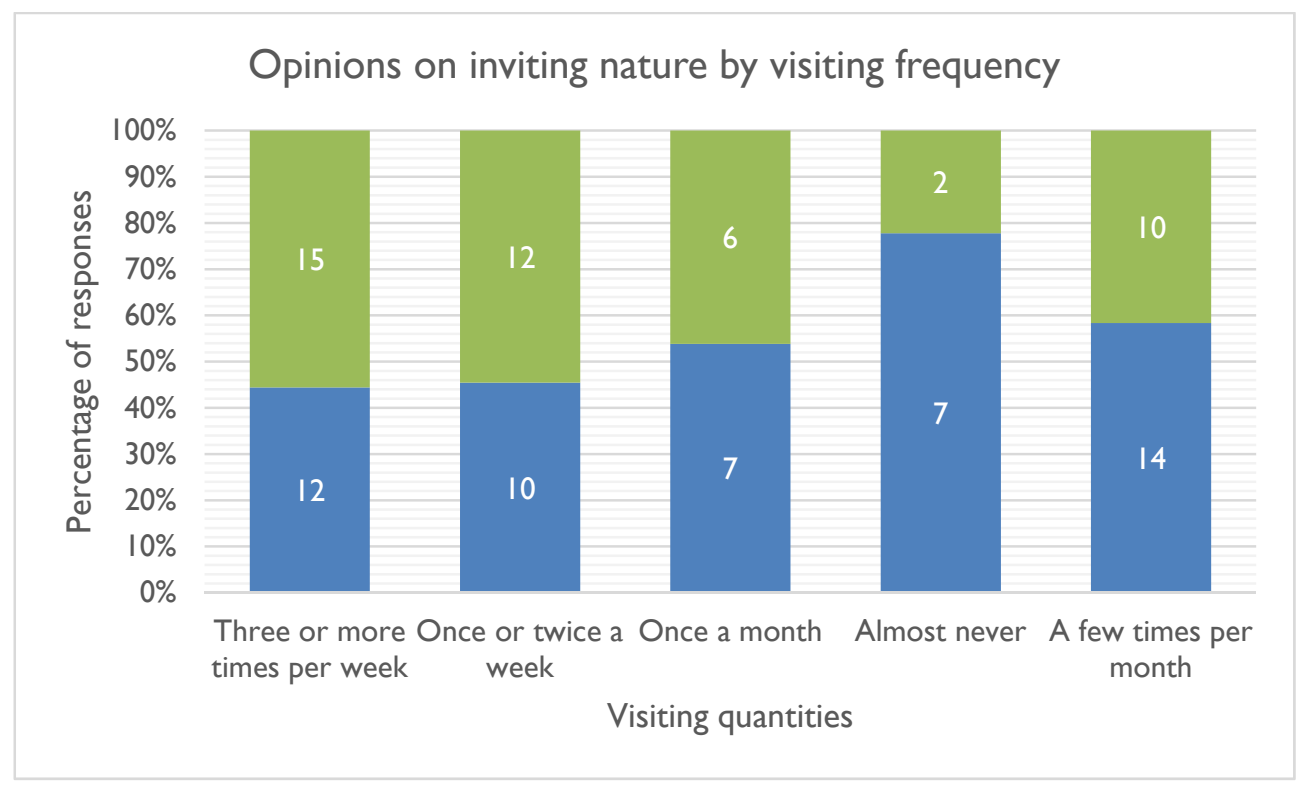

Figure 16: Visiting frequency against inviting nature of QSM

\section{Discussion}

\section{I Initial Observations}

The seating elements observed in QSM are spread throughout the main thoroughfare of the mall in three main clusters along critical access points of the space, these being the at the north-east end near Wintergarden, the intersection point of Albert Street and Queen Street and the south-western end at the entrance of the Myer Centre (refer to Figure I). Upon initial inspection these locations provide a high potential for social interaction. The ability to observe high volumes of pedestrian traffic and the position of these seating locations along the thoroughfares provides good accessibility for QSM users and high levels of observational stimulus. The seating in selected locations is built into the public space design, working with the elevation and required flow of foot traffic from the major transportation arterials. The seating design and placement feel secondary to movement through the mall, particularly in Zone I, as the shape of the seating seems to respond more to ideal movement pathways and less towards ideal seating design for encouraging social interaction (see Figure 19). The three investigated locations all use the same 
combination of materials, including wooden seats, concrete planters and stainless-steelaccented elements (see Figure 17).

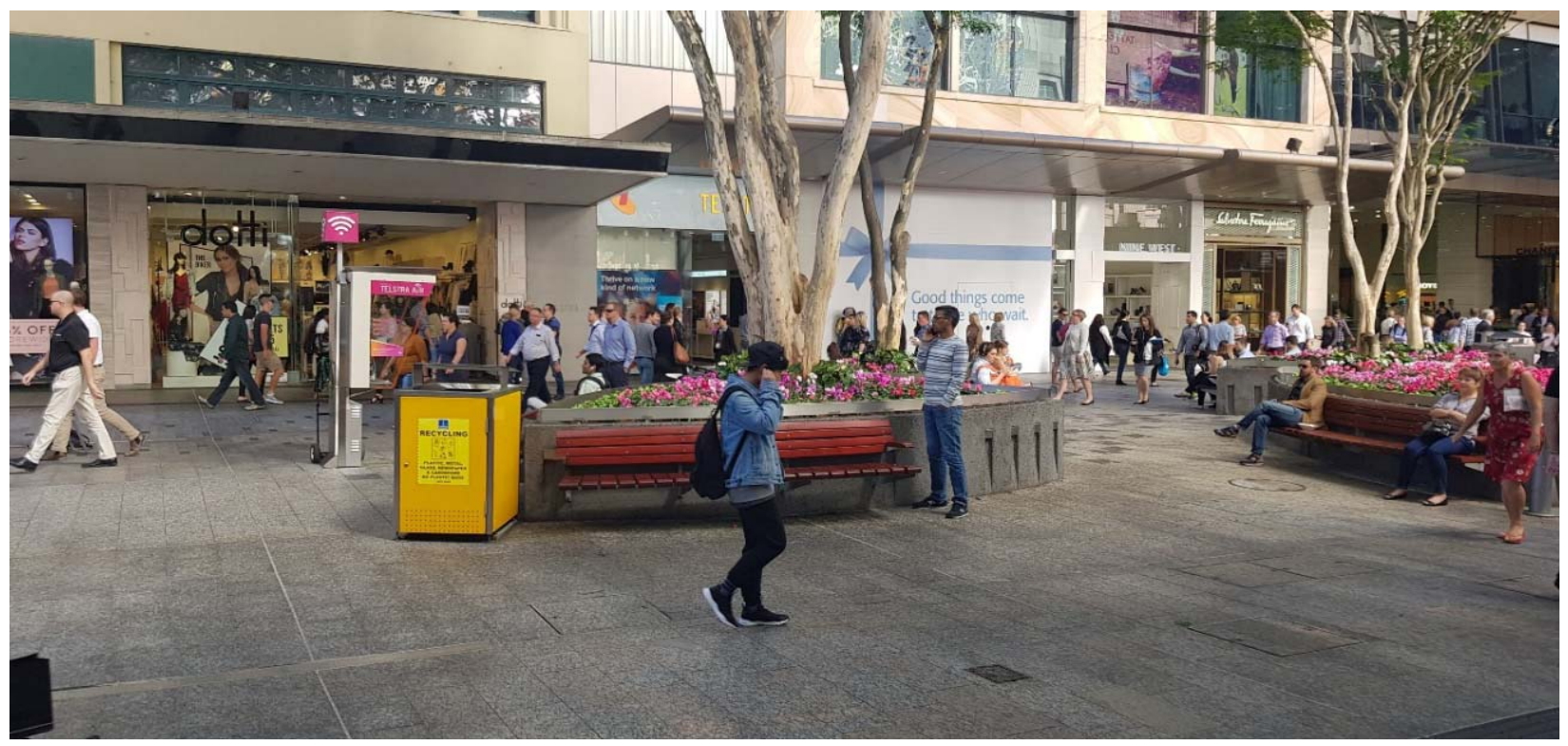

Figure 17: Seating material example, Zone 3 (Wintergarden)

\section{I.I Seating placement and design}

\section{I.I.I Location A (Myer Centre)}

By observing the seating design in Location A through the framework of Kevin Lynch's urban wayfinding theory (1960), it can be seen that the seating forms help to direct pedestrians towards the entrance of the Myer Centre, a major retail environment in QSM. Seating outside the Myer Centre is comprised of three separate seating islands which create a convex curve facing the Myer Centre entrance (see Figure 17). As seen in Figure 19, the 'edges' formed by seating elements and storefronts in Zone I create 'paths' that direct users towards the 'nodes' at entrances to the Myer Centre and Queen Adelaide Building arcade. This design creates an ideal situation for encouraging store visits but is not ideal for encouraging seating use and long-stay social behaviours in QSM's public spaces.

Further to this, initial observations suggests that the curved design of the seating causes users to face away from each other and can thus lead to the social segregation of groups. The seating appears to separate into individual segments in response to elevation changes and to avoid blocking movement between the storefront pedestrian pathways. This subtle segmenting of seats along with a convex arrangement may impede social interaction between larger groups of users ( 5 or more) and may also cause heightened feelings of segregation between the users of seating, reducing social cohesion between users. While such design traits may be unplanned or unanticipated, future works to QSM public spaces and similar environments should acknowledge these conditions generated by the seating design. 

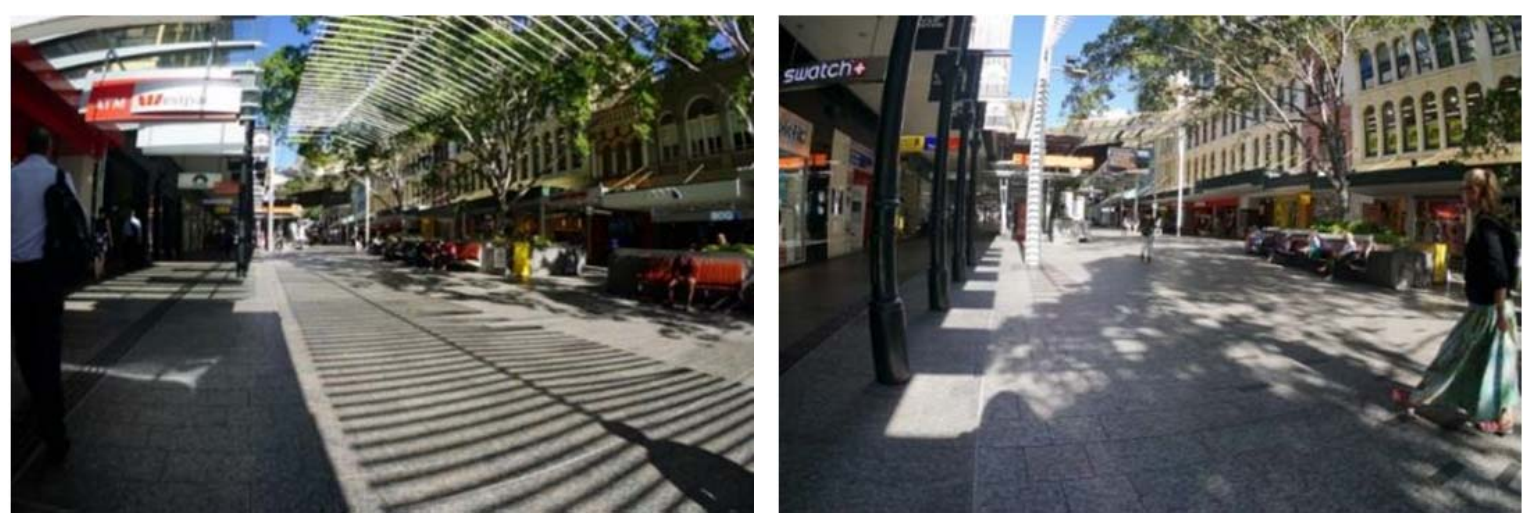

Figure 18: Seating Location A at 9:10am 23/04/2018
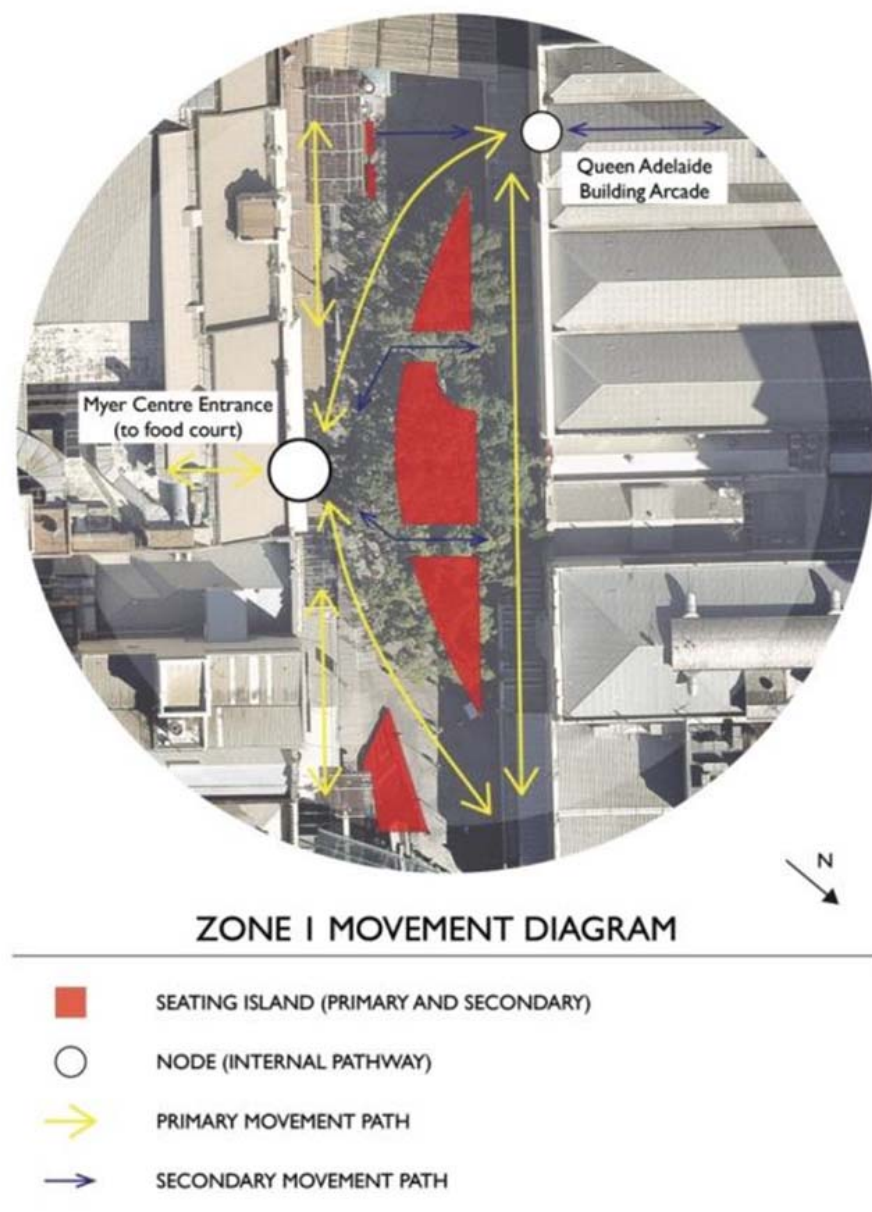

Figure 19: Movement diagram of Zone I, QSM. Seating islands form 'edges' that direct users towards retail 'nodes.

\section{I.I.2 Location B (Albert Street Intersection)}

Seating at the Albert St intersection follows the same design principles as Locations $A$ and $C$, but with different execution. Seats in this area follow a continuous run broken by 
waste bins (Figure 20) and respond to elevation changes through a continuously level seating height, causing seats on the edge of the run to be raised noticeably further off the ground plane. Unlike the other locations, forms in Location B are straight and the adjoining planter beds are used to grow small plants rather than trees for natural shading. As a result, there is no natural shading, only incidental shading from surrounding buildings. Additionally, seating in this area creates a blockage to large amounts of pedestrian flow, possibly as a means of keeping visitors in the vicinity of QSM by creating a visual 'edge'. While this positioning creates one of the more pleasant outlooks for seating users, it may also cause discomfort for some users, as pedestrian movements along Albert Street can become bottlenecked along the edges of the seating, making space around the seating overcrowded.

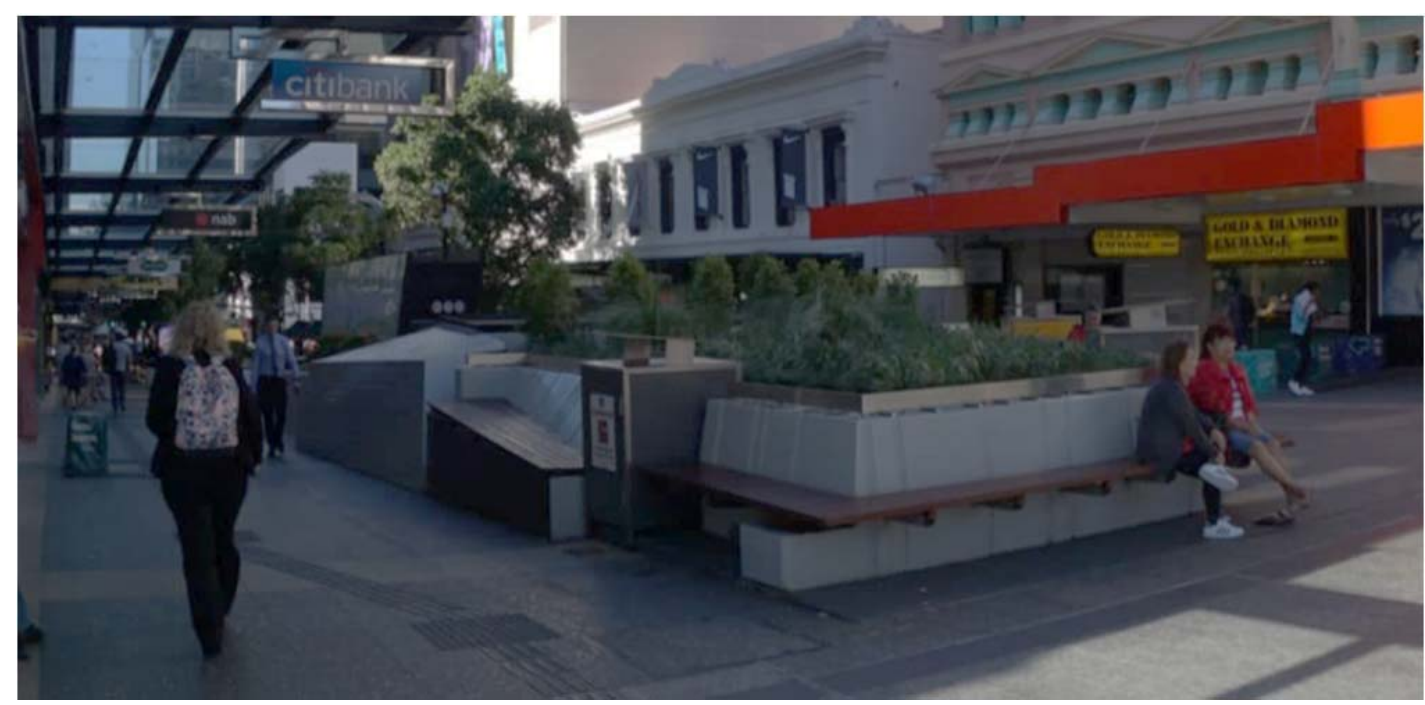

Figure 20: Seating Location B

\section{I.I.3 Location C (Wintergarden)}

Location C (Figure 2I) contains a collection of 4 irregularly-shaped garden beds with narrow walkways between them and wooden seating attached partially along some edges. The narrow pathways between raised garden beds appear to be an attempt to maximise seating in the space while avoiding the high-density pedestrian paths that connect users to the main train station (Central Station). As with Location A, the garden beds are planted with moderately-large trees that provide natural shading to the space. The curving shape of the garden beds creates convex seating arrangements facing both inwards and outwards, with inward-facing arrangements having largely unstimulating views and outlook. Additionally, inward facing arrangements rarely face other, impeding the opportunity for conversation between users of different benches. The high pedestrian flow of this area seems to attract performers and buskers, which can help improve the sociability of the space. 


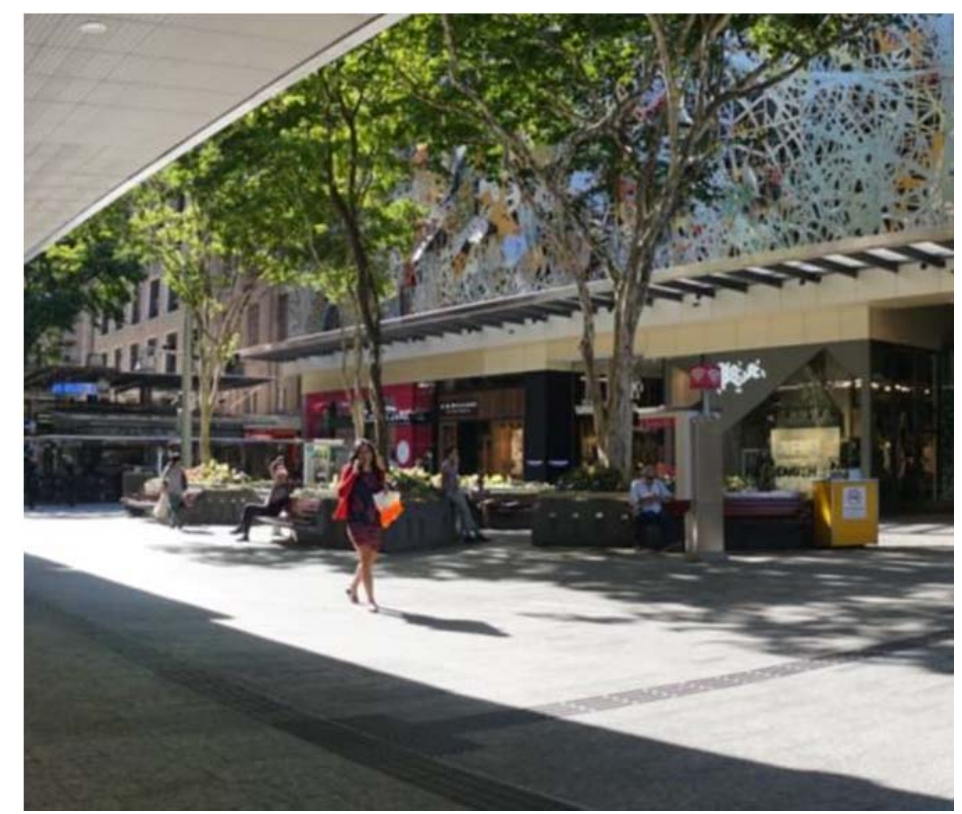

Figure 2I: Location C

\section{I.2 Saturday Social Interaction Observations}

The initial observations of seating spaces in QSM, performed on Saturday morning, $21^{\text {st }}$ April 2018, seemed to support assumptions of typical seating use by QSM users. Seating selection appeared to be most strongly dictated by the activity seating was to be used for and the most favourable conditions available. People looking for a space to perform independent activities such as eating, reading and using mobile phones were most likely to look for shaded seating to improve comfort during seating use (Gehl 20I I). This behaviour is supported by research into the role thermal comfort plays in public space (Farida 2013). For those not engaged with independent activities, seating selection was largely influenced by the stimulus available within their location. Passive observers in front of the Myer Centre were likely to sit in shaded seating to independently watch the commercial television projection, the main visual and audial stimulant within the space. In front of the Wintergarden, however, passive observers were seen to sit in direct sun in order to best watch a busker who was performing during observation time. Those watching the busker were seen talking and socially engaging with each other, activities not seen among those watching the large television. Management of QSM is strictly controlled, with buskers requiring successful auditions to be granted a busking licence (Brisbane City Council, 2018). This, combined with the QSM television and music played over speakers, suggests that the public presence of QSM is strictly manicured by management to encourage a specific usage of the space (Zhang and Lawson 2009). As the results show, the most prevalent activities during observation were independentlyperformed activities, owing largely to the available stimulus in QSM during observation.

\section{I.3 Monday Observation}

Observations carried out on the following Monday morning (23 April 2018) saw similar behaviours and instances of seating use with seating choice largely dictated by where the 
most favourable conditions were. The ambient temperature of QSM was cooler during this observation period than on the previous Saturday, so users were more spread out, with some choosing sunny seats to achieve thermal comfort (observations took place at 9am) (Farida, 20I3). With more seats exhibiting favourable conditions, users would choose to sit away from others before sitting near another seating user. Because of the long length of individual seating benches ( $\sim 3$ metres), users were often positioned at distances greater than 3.75 metres, exceeding the distance for social activities to occur naturally (Hall 1966). Additionally, instances of secondary seating use were present despite there being primary seating readily available (Figure 22). This suggests that secondary seating may be more inviting in some instances than primary seating.

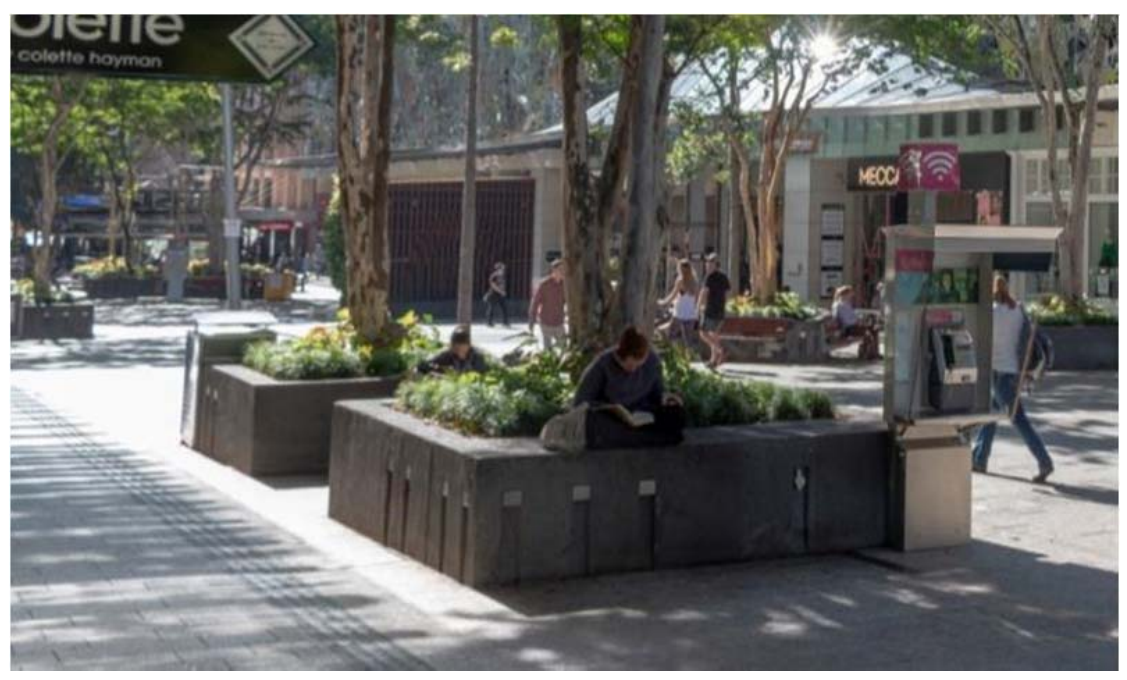

Figure 22: Instances of secondary seating

\section{I.4 Initial Observation findings and effect on further investigation}

The qualitative data collected during initial observations of QSM that its public spaces are centred more around optimising pedestrian movements and less about improving conditions for sociability and stay activities. The wide movement corridors spaced out seating elements and emphasis of impersonal visual and audial stimulus all contribute to public spaces that feel cold and impersonal (Gehl 20l I). The social effects of such an environment were evident in the behaviours and activities exhibited by seating users, who rarely chose to interact with other seating users or pedestrians. These conditions of pedestrian flow prioritisation, disconnection between users and the unwelcoming nature of space will be examined against quantitative and qualitative data from subsequent research methods to ensure that findings from these initial observations are well grounded before answering research questions.

\subsection{Online Survey Questionnaire}

The findings from the online survey back up analysis from initial observations across multiple areas. One such area is how pedestrian flow is the driving force of public space design in QSM, and a key influential factor on sociability in QSM. Short answer responses regarding public seating environments in QSM were largely negative, with several 
addressing how the fast-paced atmosphere of QSM encourages movement while discouraging prolonged stay activities (see Table 3).

Quantitative survey results also supported these opinions, showing that the majority of respondents rarely used public seating in QSM and those who did mainly performed low intensity or non-social activities, such as resting and mobile phone use (Figure 9).

Improving the quality of public seating spaces in QSM, considering factors such as seating design, planning, outlook, location, context and accessibility, could help foster a greater sense of community that, in turn, would encourage more social behaviour (Chen, Liu and Liu 2016) (Francis et al. 20I2).

In opposition to findings that QSM public spaces do not encourage extended use are survey results that suggest a small majority of the respondents $(50.5 \%)$ thought public seating effectively encouraged the use of stay activities. Other results found a direct correlation between how frequently respondents visited QSM and whether they felt that QSM was inviting to all (Figure 16). Those who frequently visited the Mall were more likely to say the Mall was inviting, while those who rarely visited felt the Mall was uninviting. This phenomenon could be explained by the large proportion of workers, residents and public transport users who responded as being frequent visitors, with very few responding as 'casual visitors' (Figure 6). These types of users would not likely be using QSM public spaces for social purposes, instead using QSM as a thoroughfare to reach their homes, transport terminals or places of employment. Additionally, these frequent users would likely be sensitized to the conditions and design of QSM. In terms of shade and shelter, survey results supported the findings from initial observations that seating environments in QSM require additional protection from direct sun, wind and rain. A majority of respondents felt that public seating in QSM was both under-shaded and under-protected from the elements (Figure II). Given the subtropical climate of Brisbane, the need for shade and protection from wind and rain in QSM is important throughout the year, indicating that additional design measures should be implemented to improve conditions for use.

Research findings suggest that users of QSM found the presence of branding and advertising in QSM public space was of little consequence to their user experience. The majority (60\%) of QSM users surveyed felt indifferent or unsure about the presence of branding and advertising in QSM public space, with the remaining respondents voicing both for and against the presence of branding and advertising in equal measure (Figure 12). This could be an indication that the retail presence in the public spaces of QSM has little effect on sociability, or that, to some extent, users feel the public spaces are an extension of the retail environment indoors. Other studies have highlighted how creating healthy public space requires the visible and audible presence of social activities rather than commercially-driven attractions, such as the commercial television projections and commercially-focused activities present in QSM (Chitrakar, Baker and Guaralda 2017; Lee, Byun and Lee 2014). Additionally, the intensive use of QSM as a travel corridor may result in elevated feelings towards the presence of advertising in its public space, by extension of the 'mere-exposure effect' (Zajonc, 1968). More research is required to understand how QSM can more harmoniously serve both retail and social functions through its inclusion, or removal, of branding and advertising from its public space. 


\subsection{Structured Observations}

The structured observations reinforced several findings made in Part A of this research project through the collection of quantitative data on seating use in QSM. Because tallies were made for instances of both seating use and pedestrian movement, an analysis of the relationship between these two areas was possible.

The relationship between pedestrian flow and time of day was as expected, with pedestrians traversing the space in greatest numbers at 12:30pm for lunchtime and 5:30pm as workers left the city (Table I). The amount of people in a space at a given time was higher than expected during peak times, with observed numbers in excess of 204 people per minute at their highest (1016 within the observed five-minute period). The lowest recordings were understandably taken at 8:30am, when most shops were not yet open. Location $C$ (Wintergarden) saw the greatest total number of pedestrians, followed closely by Location B (Albert St. intersection), while Location A (Myer Centre) saw the least. This can be attributed to pedestrians moving through Location $C$ to visit Central station, accessible towards the north-east of QSM along Queen Street. The added difficulty of recording pedestrian movements in Location $B$ due to additional directions of movement would explain why this location did not see the greatest number of pedestrian movements. Such research issues could have been remedied by conducting observations with the aid of video recordings. Overall, the pedestrian movements in QSM appear to be largely down to the schedule of an eight-hour working day, with more pedestrian movements occurring at times when CBD workers were less likely to be working (i.e. lunchtime and after $5 \mathrm{pm}$ ). From the data we collected, the quantitative data given by Brisbane City Council regarding annual visitors appears to be based in fact (Brisbane Marketing, 2015).

A comparison between the number of pedestrians and the number of seating users present during various observation periods suggests the design focus of QSM is as a pedestrian thoroughfare for surrounding businesses and services, rather than an inviting public space for stay activities. Data collected suggests that, at most, five percent (5\%) of total observed QSM users were using public seating, while the remaining $95 \%$ were pedestrians (Figure I5). The observed seating use activities also reinforced survey data, demonstrating that people using public seating in QSM require a form of stimulus to stay in the space for extended periods. Interaction with a mobile phone was consistently the highest recorded activity when seating use was observed (Figure 14). In this instance, the mobile phone is providing the stimulus required for users to perform stay activities, with such activities impeding social interaction in ones' immediate surroundings. Performances and QSM-managed events contributed to greater stay activity rates than mobile phone use, but most people engaged with these events would choose to stand, restricting the flow of traffic and causing more people to temporarily observe before moving on. These public performances and QSM-managed events were able to draw the attention of visitors for only short periods of time. Apart from mobile phone use, eating was also commonly observed, especially from I2:30 onwards (Figure 14). Given the lack of seating with tables in QSM, this suggests that seating use for eating is performed as a short stay activity, where additional facilities that benefit the eating of meals are forgone in the interest of time and seating turnover. Evidently, the design of QSM public seating appears to best serve the interests of local businesses, by restricting potential long stay activities in order to return visitors to private retail spaces as soon as possible. 


\subsection{Mobile Phones}

A critical finding from the research was the wide-spread use of mobile phones in public spaces, prompting us to consider how the use of mobile phones might be able to support social behaviour in public spaces like QSM. Further research investigating how mobile phone use undermines the enjoyment of face-to-face social interaction suggests that, while mobile phones are not fundamentally antisocial, their use isolates users from their surroundings, decreasing social engagement in public spaces (Dwyer et al., 2018). Findings from our study suggested that mobile devices and digital technologies could be valuable tools to inspire social behaviour in public retail environments and cities in general. Prior research has stated that mobile phone use for social engagement is a relatively new phenomenon, with the relationship between social interaction and human-computer interaction within shopping environments not fully understood $(\mathrm{Ng}, 2003)$. Additionally, the rise of online shopping poses a risk to QSM and other physical retail environments, but mobile devices could be part of the solution to maintaining the economic and social longevity of these spaces. Some studies show that mobile devices and digital technologies have the potential to offer both economic and social benefits (Misra, et al., 2016), which could support public retail environments like QSM by improving the sociability of the retail experience. Studies investigating the effects of over-reliance on technology suggest that further research is needed to understand how people can best receive the social benefits possible from mobile phone use in non-digital environments (Kushlev et al., 2017). Given the wide-spread adoption of smart devices worldwide, further research into ways of supporting social behaviour in public spaces through mobile phone use should be conducted to better understand this increasingly relevant issue.

\section{Conclusion}

As discussed, Queen Street Mall is not adequately designed to support social behaviour between users. By prioritising the design of its public spaces to best support pedestrian pathways and the interests of retailers, the economic aspects of the mall overwhelm the social and civic functions, to the detriment of sociability and sense of community among users (Friesen 2017). Research findings suggest that increased shading, shelter and a redesign of seating to focus on encouraging prolonged stay activities would improve the sociability of the Mall. With growth projections suggesting the population of Brisbane will more than double over the next 45 years (Australian Bureau of Statistics 20I3), it is increasingly important that seating environments in Queen Street Mall are improved in order to better accommodate the public space needs of locals and frequent visitors. A critical finding from research was the wide-spread use of mobile phones in public spaces. The nature of mobile phones as a tool for connecting users separated by location appears to result in a disconnection from a users' immediate surroundings. As observations show, this results in anti-social behaviour from users of mobile phones, negatively impacting the social effectiveness of public space. Given the wide-spread adoption of smart devices worldwide, further research into ways of supporting social behaviour in public spaces through mobile phone use should be conducted to better understand this increasingly relevant issue.

Due to several research constraints, findings made in this research project should be considered as a catalyst to further analysis into the sociability of public seating spaces in 
Queen Street Mall. Additional observations carried out over a broader range of days, seasons and weather conditions, along with increased sample sizes, would help develop a more comprehensive analysis of the social effectiveness of the Mall. The qualitative data collected through online surveys could also be enriched by conducting on-site interviews with QSM visitors. Additional research into social science fields such as mere-exposure effect and consumer theory in relation to public space design would also help build on research findings.

\section{Appendix}

Table 2: Online survey questions in full

\section{Survey Questions}

\section{Types of users}

I. Which age groups do you fit within?

2. Which gender do you identify as?

What type of person are they? (resident, employee, casual visitor)

\section{The use of seating in QSM}

I. How frequently do you visit Queen Street Mall?

2. When do you generally visit Queen Street Mall?

3. When you visit the Mall, how often do you use the public seating?

4. What activities do you use the seating for?

5. Do you ever use 'secondary seating' elements in the Mall instead of proper seating?

6. Additional comments about your use of public seating in Queen Street Mall?

\section{Perceptions of Seating Environments}

7. Do you find there is public seating available when you want it?

8. Do you feel Queen Street Mall is well designed to facilitate stay activities?

9. Based on your use, do you feel that the public seating in the Mall is sufficiently shaded on sunny days?

10. Based on your use, do you feel that the public seating is sufficiently protected from wind and rain?

II. Do you feel that the public spaces in Queen Street Mall are inviting to all users?

12. Do you feel that the presence of branding and advertising in Queen Street Mall enhances or detracts from the user experience? Do you have any comments regarding your perception of branding and advertising in Queen Street Mall?

\section{Other}

Additional comments regarding do you have any additional comments to make regarding the seating environments in Queen Street Mall? 
Table 3: Use case quotes

\section{Users cases in the QSM:}

\section{Quotes}

"It's unwelcoming and always been a bit dodgy. I wouldn't really want to sit in queen street ever. I only use it to get from one place to another."

"Public seating in Queen Street Mall can be quite dirty; people often leave trash or bits of food on the seats, so I often avoid this area if I can."

"Not many comfortable seated spots, there isn't really much shade either when during the heat of summer."

"The mall is not public friendly and stopping to sit down and relax is hard when people are walking pass all the time."

"I don't find that to be too clean to feel comfortable using them unless I really have to. Plus, it seems there could have been more seatings as sometimes it is always full".

Table 4: User experience quotes

\section{User experience and branding presence in QSM: Quotes}

"I think shops should be allowed their advertising on their shopfronts, and signs pointing to where large shops are. But not too much in regard to billboards as it does retract from the beauty and architecture in the area"

"The more creative/bright and engaging displays are the more interesting the mall is."

"Have the brands deliver or enable a service e.g. Wireless fast-charging or userinteraction rewards like coupons for nearby stores."

"I understand that the purpose of Queen Street Mall is to bring public presence to retail outlets, however, these days the high use of advertisements around the mall (especially the food court) makes the place feel overwhelming and disorganised. It lacks architectural, or interior intent (there's no experience) and feels like the mall is being overrun by ads \& marketing tactics. (I feel like I'm only wanted as a customer, not a visitor).

A mall that best deters from this is Garden City. Their outdoor food plaza brings life, spirit and a euphoric experience for visitors. (I feel like I'm being invited to enjoy myself rather than rush to complete all my errands)"

"I believe when people are on move they hardly have time to get into any details of any advertisements for which some can go unnoticed. Bold, Catchy, Friendly, Visible and at right spot can help boost the way people perceive adverts. It is informative and where people can feel comfortable relating to what is on offer." 
Table 5: Seating environment Quotes

\section{Seating Environment in the}

\section{QSM: Quotes}

"I believe it's not that difficult to find a seat as it's not a super appealing space to sit in, there's no quiet spaces especially at lunchtime.

"It is a very busy walkway which can be frustrating during peak hours, so more seating should be accessible but keeping in mind to not block those passing through."

"Seating can serve more of an active purpose; user interaction and engagement with nearby businesses. Wireless charging pads present the opportunity for secure, embedded NFC tags controlled and secure - that may open avenues for marketing and analytics outcomes, enrich cultural participation and awareness, and support local business presence within the hub."

"They seem designed to discourage use beyond a short amount of time.

"There is not enough seating and green spaces, there is a lot of overcrowding in the Mall with people basically standing around in groups, it seems like the Mall is more of an advertising for a shopping mecca then a general green relaxation area."

"They (the seating) need to be shaded and covered from rain

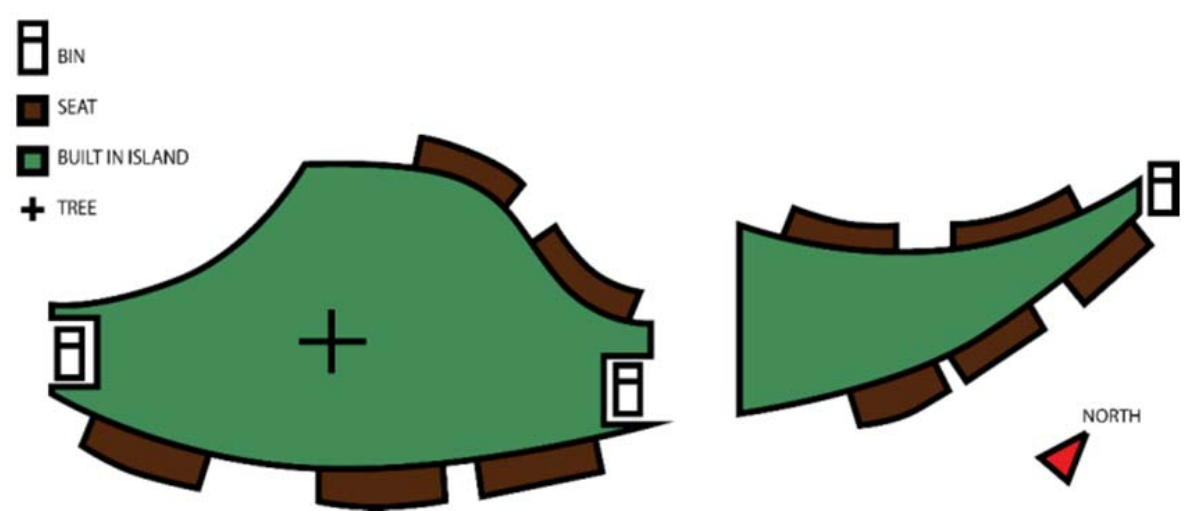

Figure 23: Seating Location A diagram 


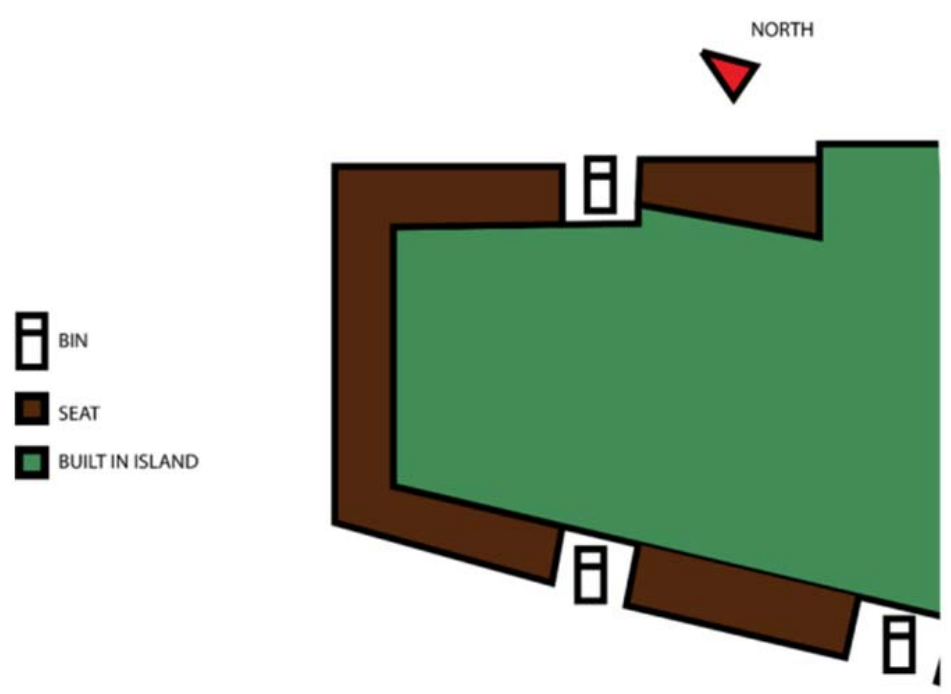

Figure 24: Seating Location B diagram

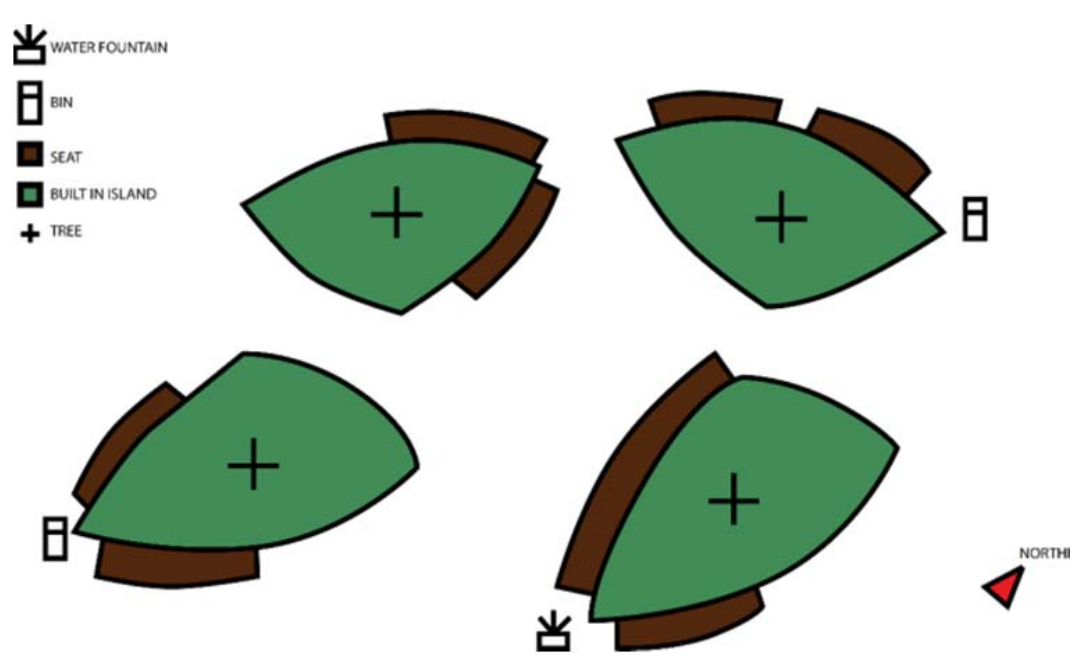

Figure 25: Seating Location C diagram

\section{Acknowledgements}

The research team would like to acknowledge research coordinator Francisca Rodriguez for sharing her knowledge on academic writing and research. Acknowledgements are also extended to those who participated in the online survey and on-site interviews and the extended teaching team for DEH70I Research Methods at QUT. 


\section{References}

Australian Bureau of Statistics (2013). Media Release - Australia's population projected to double by 2075 (Media Release) [online].

http://www.abs.gov.au/ausstats/abs@.nsf/lookup/3222.0Media\%20Releasel2012\%20(base)\%20t $0 \% 20210$.

Brisbane City Council (2014). Busking in malls. https://www.brisbane.qld.gov.au/laws-permits/lawspermits-businesses/queen-street-valley-malls-management/malls-forms/busking-malls.

Brisbane Marketing (20I5). Queen Street Mall Visioning Plan. https://www.brisbane.qld.gov.au/sites/default/files/20150629-queen-street-mall-visioning 0.pdf

Chen, Y., Tao, L. and Weibin, L. (20I6). Increasing the use of large-scale public open spaces: A case study of the north central axis square in shenzhen, china, Habitat International 53: 66-77. https://doi.org/10.1016/i.habitatint.2015.10.027.

Chitraka, R. M., Baker D. and Guaralda, M. (2017). Emerging challenges in the management of contemporary public spaces in urban neighbourhoods, International lournal of Architectural Research I I ( ): 29-43. http://dx.doi.org/I0.26687/archnet-iiar.vI Iil.II 97.

Dwyer, R., Kushlev, K., Dunn, E. W. (2018). Smartphone use undermines enjoyment of face-toface social interactions, lournal of Experimental Social Psychology, 78, 233-239. https://doi.org/10.1016/i.jesp.2017.10.007

Farida, N. (2013). Effects of outdoor shared spaces on social interaction in a housing estate in Algeria, Frontiers of Architectural Research 2(4): 457-467. https://doi.org/10.1016/i.foar.2013.09.002.

Friesen, M. (2017). The contested public space of shopping streets: The case of Købmagergade, Copenhagen." Journal of Landscape Architecture 12(2): 18-31. https://doi.org//0.1080/18626033.2017.136/082

Francis, J., Giles-Corti, B., Wood, L. and Knuiman, M. (20I2). Creating sense of community: the role of public space, Journal of Environmental Psychology 32(4): 40I-409.

https://doi.org//0.1016/j.jenvp.2012.07.002. 
Effects of outdoor seating spaces on sociability

Gehl, Jan (20I I). Life between buildings: Using public space. Washington: Island Press.

Huang, I., Zhou, C., Zhuo, Y., Xu, L., and liang, Y. (2016). Outdoor thermal environments and activities in open space: An experiment study in humid subtropical climates. Building and Environment 103: 238-249. https://doi.org// 0.1016/i.buildenv.2016.03.029.

Kushlev, K., Proulx, J.D.E., Dunn, E.W. (2017). Digitally connected, socially disconnected: The effects of relying on technology rather than other people. Computers in Human Behavior, 76, 6874. https://doi.org/10.1016/i.chb.2017.07.001.

Lee, Yunjeong, Kyeonghwa Byun and Seungeun Lee (2014). Use of Seating Spaces on Shopping Streets in Japan. International Information Institute (Tokyo). Information 17(9): 4227-4234.

Lin, Tzu-Ping (2009). Thermal perception, adaptation and attendance in a public square in hot and humid regions. Building and Environment 44(I0): 2017-2026. https://doi.org//0.1016/i.buildenv.2009.02.004.

Lynch, K. (1960). The image of the city. Cambridge, Mass: MIT Press

Misra, S., Cheng, L., Genevie, J., \& Yuan, M. (2016). The iPhone Effect: The Quality of In-Person Social Interactions in the Presence of Mobile Devices. Environment and Behavior, 48(2), 275298. Retrieved February 02, 2018, https://doi.org//0.1177/00139/65/4539755

$\mathrm{Ng}$, C.F. (2003). Satisfying shoppers' psychological needs: From public market to cyber-mall, Journal of Environmental Psychology. 23(4), 439-455. https://doi.org/I0.1016/S02724944(02)00102-0

Rasidi, Mohd H., Nurzuliza I.h and Ismail Sai (20/2). Urban green space design affects urban residents' social interaction. Procedia - Social and Behavioral Sciences, 68: 464-480. https://doi.org/10.1016/i.sbspro.2012.12.242.

Zajonc, R. B. (1968). Attitudinal effects of mere exposure, Journal of Personality and Social Psychology, 9(2, Pt.2), pp. I-27. doi: 10.1037/h0025848.

Zhang, W. and Lawson, G. (2009). Meeting and greeting: Activities in public outdoor spaces outside high-density urban residential communities. Urban Design International, 14(4), 207-2 I 4. https://doi.org//0.1057/udi.2009.19 